NBER WORKING PAPER SERIES

\title{
CAN GREATER ACCESS TO EDUCATION BE INEQUITABLE? NEW EVIDENCE FROM INDIA'S RIGHT TO EDUCATION ACT
}

\author{
Chirantan Chatterjee \\ Eric A. Hanushek \\ Shreekanth Mahendiran \\ Working Paper 27377 \\ http://www.nber.org/papers/w27377 \\ NATIONAL BUREAU OF ECONOMIC RESEARCH \\ 1050 Massachusetts Avenue \\ Cambridge, MA 02138 \\ June 2020, Revised December 2020
}

Chatterjee acknowledges the support of the 2018-2019 Campbell and Edward Teller National Fellow Program \& the 2019-2020 Visiting Fellow Program at Hoover Institution, Stanford University and the ICICI Bank Chair in Strategic Management at IIM Ahmedabad. Mahendiran acknowledges support from CBPS, Bangalore, India. The authors thank some anonymous tuition center entrepreneurs for their time with descriptive telephonic interviews with Mr. Rakesh P and appreciate his research assistance. Sachidananda Benegal, doctoral student from IIM Bangalore provided his very insightful inputs on the Registrar of Companies database of the Ministry of Corporate Affairs, Government of India. We also acknowledge very insightful comments from Wilima Wadhwa and Rukmini Banerji from ASER-PRATHAM in India in private conversations with us. We are very grateful to Abhijit Banerjee, Sourav Bhattacharya, Shengmao Cao, Anindya Chakrabarti, Radhika Joshi, Reetika Khera, Anant Mishra, Naveen Reddy, and Manisha Shah for their input. The views expressed herein are those of the authors and do not necessarily reflect the views of the National Bureau of Economic Research.

NBER working papers are circulated for discussion and comment purposes. They have not been peer-reviewed or been subject to the review by the NBER Board of Directors that accompanies official NBER publications.

(C) 2020 by Chirantan Chatterjee, Eric A. Hanushek, and Shreekanth Mahendiran. All rights reserved. Short sections of text, not to exceed two paragraphs, may be quoted without explicit permission provided that full credit, including $\odot$ notice, is given to the source. 
Can Greater Access to Education Be Inequitable? New Evidence from India's Right to Education Act

Chirantan Chatterjee, Eric A. Hanushek, and Shreekanth Mahendiran

NBER Working Paper No. 27377

June 2020, Revised December 2020

JEL No. H4,I25

\begin{abstract}
India moved to a constitutional guarantee of universal basic education with the Right to Education (RTE) Act in 2009 that called for full access of children aged 6-14 to free schooling. This paper considers the offsetting effects from induced expansion of private tutoring that limited gains in educational equity from RTE. We develop a unique database of registrations of new private educational institutions offering tutorial services by local district between 2001-2015. We estimate the causal impact of RTE on private supplemental education by comparing the growth of tutorial institutions in highly competitive educational markets to that in less competitive educational markets. We find a strong impact of RTE on the private tutoring market and show that this holds across alternative definitions of highly competitive districts and a variety of robustness checks, sensitivity analyses, and controls. Finally, we provide descriptive evidence that these private tutoring schools do increase the achievement (and competitiveness) of students able to afford them.
\end{abstract}

Chirantan Chatterjee

Indian Institute of Management, Ahmedabad

Room 15F, Wing 15, Heritage Campus

Ahmedabad

India

and Stanford University

chirantan@gmail.com

Eric A. Hanushek

Hoover Institution

Stanford University

Stanford, CA 94305-6010

and NBER

hanushek@stanford.edu
Shreekanth Mahendiran

University of Lausanne

shreekanth.mahendiran@unil.ch

A online appendix is available at http://www.nber.org/data-appendix/w27377 


\section{Introduction}

Decision makers in virtually all countries of the world see the development of human capital as key to future economic prosperity, but they face uncertainty about what policies will best meet the sometimes conflicting goals of expanding access, improving quality, and lessening disparities in their schools. This conundrum is most severe in developing countries where resource constraints are binding. These governmental policy problems are further complicated by the fact that affected individuals respond to the educational incentives they see and may take actions that interact both positively and negatively with government programs. This paper investigates private reactions through expansion in private tutoring to India's rapid governmental expansion of educational access. In particular, we investigate whether the increased demand for private tutoring induced by new schooling guarantees works to offset the equity enhancing impacts of increased access to elementary education.

All of the issues of access, quality, and private reactions came into play when India passed a 2009 constitutional amendment ensuring a "right to education" for all and set in motion both public and private adjustments to new educational policy requirements. India's Right to Education Act (RTE) was designed to ensure a constitutionally-guaranteed right to pursue basic education (up to eighth grade) for all children. Government schools had to be entirely free, and students could not be retained in grade or expelled. It also set minimal input quality standards defined by physical facilities, teacher background, and maximum class sizes, and it required private schools to accept poor students up to one-quarter of their student body at first grade.

While the data are not perfect, Shah and Steinberg (2019) document a series of trends associated with the RTE. ${ }^{1}$ They conclude that RTE led to significant increases in student enrollments along with a continuation in movement out of government schools and into private schools. Although not directly attributable to RTE, Kingdon (2017) also finds significant declines in government school students between 2011 and 2016 that were matched by

\footnotetext{
${ }^{1}$ Data on schooling in India may be pieced together from alternative sources and are not necessarily consistent across sources (see Kingdon (2017) and Shah and Steinberg (2019)). The most reliable overall data come from the National Sample Survey (NSS), an annual household survey. The official school data come from the District Information System on Education (DISE), which is an administrative data set of the Indian Ministry of Education, although the accuracy and comprehensiveness of the DISE data have been questioned. These data can be supplemented with achievement data from the India Human Development Survey (IHDS).
} 
significant increases in private school enrollment over the same period. ASER achievement data for rural populations show significant declines in achievement since RTE with larger declines found in government compared to private schools (Kingdon (2017), Shah and Steinberg (2019)). ${ }^{2}$

Our primary interest, however, is focused on the causal impact of RTE on the expansion of supplemental educational services, primarily through private tutoring. Large scale private tutoring is common in many countries of the world (Bray (1999), Kim and Jung (2019), Zhang and Bray (2020)). This supplemental education is often called "shadow education," reflecting the close connection to and dependence on the government education system and its learning objectives. Importantly, however, even with increased research and government interest in the area, there are limited and sketchy data and a lack of generalizable research on even the most fundamental aspects of shadow education such as extent, subject focus, cost, or outcomes. ${ }^{3}$ Even the nomenclature differs; Kobakidze and Suter (2020) note that there are 22 different names applied to private, out-of-school institutions around the world. ${ }^{4}$

Individual studies indicate considerable heterogeneity both within and between countries in the form and outcomes of shadow education (Bray (1999), Kim and Jung (2019)). As a result, judgments about the system as a whole vary considerably. Critics suggest that these private tutoring schools reinforce and perpetuate social inequities and at times may even distort instruction in the traditional schools. Supporters point to the increase in learning and human capital produced by them along with the possibility of even reducing the load on the traditional teachers. ${ }^{5}$ This range of opinion suggests that overall judgements about the impact of shadow education rest on the balance between impacts on learning outcomes and impacts on the distribution of outcomes. As a result, government responses to private tutoring range from outright bans on private tutoring to active government encouragement (Dang and Rogers (2008)).

Nonetheless, there is no disagreement that private tutoring leaves out a portion of the

\footnotetext{
${ }^{2}$ The Annual Status of Education Report (ASER) is a household survey by the Pratham Education Foundation (https://www.pratham.org/) focusing on rural education and including student test data.

${ }^{3}$ As an example of the increasing interest in the topic, the European Journal of Education devoted an entire special issue to shadow education in September 2020 (https://onlinelibrary.wiley.com/toc/14653435/2020/55/3).

${ }^{4}$ These alternate names include among others shadow education, juku in Japan, hagwon in Korea, private tuitions in India, and cram schools in more common vernacular.

${ }^{5}$ The interaction of private tutoring with regular schooling of course is not always positive. Jayachandran (2014) finds that learning can be less in the regular classrooms when teachers are also providing private tutoring.
} 
population that cannot afford the tuition. Importantly, this excluded population is precisely the focus of the Right to Education Act, meaning that private responses directly offset at least a portion of the government actions designed to promote more educational equity. We exploit the implementation of the Right to Education Act (RTE) in India in 2009 to trace the causal impacts of increased access to schooling on equity-reducing expansions of private tutoring.

Our analysis builds on an original, newly-constructed database of educational start-ups. This database tracks the entry of private tutorial centers across 374 (U.S. county-like) districts in 30 states/union territories of India. It uses official monthly administrative statistics compiled by the Ministry of Corporate Affairs of the Government of India (GoI) on firm registrations in the education sector between 2001 and 2015. These data are merged with information on existing district demographic and economic characteristics. Our empirical analysis employs a difference-in-differences approach to estimate the causal impact of the RTE on the expansion of private tutorials.

Our identification strategy is motivated by prior analyses that point to individuals' use of private tutoring to do better on high-stakes exams and to gain a competitive advantage over peers (Kim and Lee (2010), Azam (2016), Bray (2017), Ghosh and Bray (2018), Bhorkar and Bray (2018)). With the increased competition from expansion of student access after RTE, one expects a differential response of students that reflects previous levels of peer competition. Our main analysis focuses on districts where Indian Institutes of Technology (IIT's), the most prestigious engineering institutions, are located. These very selective institutions of higher education make school admissions in these districts particularly competitive. ${ }^{6}$ We define these districts as educationally competitive districts and compare the consumer reliance on private tutorials in them to that in less educationally competitive districts without such institutions. A regression-based pre-trends analysis with data prior to the expanded access of RTE supports a causal interpretation of these findings.

With the expansion of school access from RTE, we find that the number of private

\footnotetext{
${ }^{6}$ The approach is related to work on school attendance in U.S. studies where the influence of local colleges on school attendance is well-documented (see, for example, Card (1993), Carneiro, Heckman, and Vytlacil (2011), Doyle and Skinner (2016)). As is clearly laid out in the 1961 IIT Act, entrance to IIT's is national so that, for example, a student from Northern India is completely free to choose IIT Chennai in Southern India as an option (see https://en.wikipedia.org/wiki/Institutes_of_Technology_Act, 1961). Nonetheless, the costs of movement and cultural similarities plus informational asymmetries induce a regional stickiness of students in each region's IITs. Moreover, Bhorkar and Bray (2018) find evidence that the tuition centers also provide advice on school choice, reinforcing local competition.
} 
tutoring centers, called tuition centers in India, expanded at a monthly rate of 35 per billion persons in our educationally competitive districts (compared to less competitive districts). For the post-RTE period through 2015 this conservatively implies an expansion of tuition students in the 13 IIT districts of some 113,250. Underscoring the degree of educational competition, while India has a wide range of tertiary schools, the IIT's themselves enroll less than ten percent this number of new tutoring students.

We also examine the effects of RTE on the entry of other educational units, i.e. private schools and higher educational institutions (HEI). We find positive effects of the introduction of RTE on private school registrations. ${ }^{7}$ We also find significant and positive impact on new registrations of higher educational institutions in our main specifications, but this is not consistent across some of the robustness checks. These weaker results may simply reflect variation in entry costs, since entrepreneurs need to procure licensing and permissions from local or state government, something that is much less burdensome for tuition centers.

In robustness analysis, we use alternative definitions of educationally-competitive districts: the prior existence of any new registrations of tuition centers, private school, or higher education institutions between 1991 - 2000, and the existence of a broader set of elite education institutions (Institutes of National Importance in India). ${ }^{8}$ Additional robustness checks consider alternative allowance for the varying population size of districts and the staggered nature of implementation of RTE in India by state. For each, we find consistently strong causal evidence that RTE induced an expansion of private tutoring.

Finally, using descriptive evidence from the India Human Development Survey (IHDS) dataset in India, we establish how the competitive margin plays a role in increasing the demand for tuition centers from households in competitive districts, which then explains the increase in tuition centers registrations evidenced from our primary regression estimations. In addition, we provide descriptive evidence that the new tuition centers in the educationally competitive districts do appear to contribute to better student performance. These findings, however, need to be treated with caution because of the limitations of the IHDS data.

In the next sections, we provide institutional background of RTE and a discussion of

\footnotetext{
${ }^{7}$ Note, however, that we analyze registered private schools and do not consider unregistered schools, which may be substantial in some locations (e.g., see Rangaraju, Tooley, and Dixon (2012)).

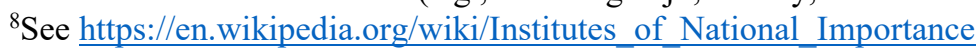


private tutoring in India. Section 4 presents our empirical strategy, and section 5 describes the construction of our database. Sections 6 and 7 provide the main empirical results and the robustness analyses, respectively. These are followed by a series of extensions and a concluding discussion.

\section{The Right to Education in India}

The educational challenges to India are well known. While India has not been a recent participant in international testing, the available evidence leads strongly to a conclusion of low overall performance. Das and Zajonc (2010) construct tests that are comparable to the TIMSS assessments and find that students in the states of Odisha and Rajasthan perform very poorly in international comparisons, particularly at the lower parts of the achievement distribution. Students in Himachal Pradesh and Tamil Nadu states participated in the 2009 PISA tests and ranked at the bottom of the world distribution (Hanushek and Woessmann (2015b)). Finally, Singh (2020) documents the low productivity of Indian schools (in Andhra Pradesh state) compared to schools in Vietnam and Peru.

In 2000, just 86 percent of Indian children were in primary schools, and the survival rate to grade 5 was 47 percent (UNESCO (2003)), underscoring India's longstanding challenge in providing broad access to schooling. With the worldwide push for expanded access in the Educational for All Initiative (UNESCO (2000a)), India began a push for universal access.

Passing the Right to Education Act followed a complicated path described in Appendix A, but the key features for our purposes are easily summarized. In 2002, there began discussion of adding the $86^{\text {th }}$ amendment to the constitution to introduce Article 21(a) that held that "the State shall provide free and compulsory education to all children of the age of six to fourteen years in such manner as the State may, by law, determine." 9 The RTE Act was first presented to the Indian parliament in 2006, but it was rejected with lack of funds cited as the official reason. ${ }^{10}$ However, the RTE Act gained approval from the Union Cabinet in 2008 and then passed through the Lower and Upper Houses of parliament in July and

\footnotetext{
${ }^{9}$ https://www.india.gov.in/my-government/constitution-india/amendments/constitution-india-eighty-sixthamendment-act-2002 - [Accessed as on March 14 $\left.{ }^{\text {th }} 2019\right]$.

${ }^{10}$ See: https://timesofindia.indiatimes.com/india/Centre-buries-Right-to-Education-Bill/articleshow/1748745.cms [Accessed as on June $3^{\text {rd } 2020]}$
} 


\footnotetext{
${ }^{11}$ Details can be found in Jha, Ghatak, Mahendiran, and Bakshi (2013) and are summarized in Appendix A.

${ }^{12}$ Private unaided schools are those which are managed by private management and does not take any assistance from the state or central government in any form.

${ }^{13}$ Rangaraju, Tooley, and Dixon (2012) describe the private unaided schools that offer education services to 65 percent of children in Patna, Bihar. They neither have the infrastructure nor qualified teachers to meet the RTE mandates. The enforcement of RTE has led to closing down of such schools or leaving them to continue as illegal entities without the proper recognition from the local government. On the other hand, the public schools may not have faced such stringent requirements.
} 
schooling - an equity-enhancing move of the government - induced better off families to seek private education supplementation in order to secure a competitive advantage - an offsetting equity-reducing action by the families. The Indian schooling system is quite hierarchical and relies on a series of examinations at multiple points in the schooling process to determine continuation and placement of students. Private tutoring is one way in which better off families can maintain a competitive advantage in school placement in the face of increased competition. Here we provide context for the status of private tutoring in India.

While supplementary education is widely consumed around the world, there are limited consistent data on the extent and character of such education, in part because of varying definitions (Bray, Kobakhidze, and Suter (2020)). Perhaps the most consistent data on supplemental education is found in the survey accompanying the OECD international testing of the Programme for International Student Assessment (PISA) in 2012. It asked 15-year-old students how many hours per week they spent in out-of-school classes that were offered by a commercial company and paid for by students' parents. The percentage of students participating in such education ranged from four percent in Finland to over 50 percent in Thailand and Greece (Park, Buchmann, Choi, and Merry (2016)).

The nature and institutional structure of shadow education differs significantly across countries, and this leads to few generalizations that apply around the world. There are a large number of evaluations and assessments for individual countries, but these have been largely descriptive with few quantitative studies of the impact of supplementary education. A number of international reviews summarize the range of experiences (e.g., Bray (1999, (2017), Dang and Rogers (2008), Park, Buchmann, Choi, and Merry (2016), Kim and Jung (2019), Zhang and Bray (2020)).

In India, there has been a long tradition of private tutoring - called "private tuitions" in India - since the 1980s (Azam (2016)). There has been a gradual increase in accessing private tuition by students across the different education levels leading to 13, 20, 30 and 31 percent of students attending primary, middle, secondary and senior secondary levels, ${ }^{14}$ respectively, by 2007-08. There also exists large variation across the 29 states and 7 union territories in India. West Bengal leads with 75 percent of students accessing private tuition,

\footnotetext{
${ }^{14}$ Primary levels include grades between 1-5, Middle levels include grades between 6-8, Secondary levels include $9^{\text {th }}$ and $10^{\text {th }}$ grade, and Senior Secondary levels include $11^{\text {th }}$ and $12^{\text {th }}$ grades.
} 
and Mizoram is at the other end of the spectrum with 3 percent in 2014 (Government of India (2016)).

Analyses in both India and other countries point to varying motivations for participation in private tutoring, but they invariably bring up competition for further education. In fact, the Indian education system has been described recently as one primarily of selection: "the majority of the education system is driven by 'sorting' rather than 'human development" (Muralidharan (2019)). A recent report indicated that parents in India lack trust in government schools and spend as much as 35 percent of household income on private schooling and supplemental education. ${ }^{15}$ The Indian data show relatively higher numbers of students employ private tuitions when they attend tenth and twelfth grades. These grades have high-stakes examinations that are an important determinant to each student's pursuit of desired academic streams at the tertiary level and of chances to gain entry in more prestigious higher education institutions. For example, Ghosh and Bray (2018) find in a sample of students from Bengaluru, India, that the top reason for participating in private tutoring was to score high marks on examinations, a response of 80 percent of Grade 10 students.

Similarly, in assessing the rise in private tutoring in West Bengal (the largest state of usage of private tutoring), Amartya Sen (2009) notes:

Underlying this rise is not only some increase in incomes and the affordability of having private tuition, but also an intensification of the general conviction among the parents that private tuition is "unavoidable" if it can be at all afforded (78 per cent of the parents now believe it is indeed "unavoidable" - up from 62 per cent). For those who do not have arrangements for private tuition, 54 per cent indicate that they do not go for it mainly - or only - because they cannot afford the costs. (p. 13)

From surveying parents in 2008/09, the Pratichi (India) Trust reports: "The felt need of private tuition was so high that even in schools where parents thought that the performance of the teachers were extraordinarily good also thought that private tuition was still needed for 'even better performance of the children'.” (Pratichi Research Team (2009))

Azam (2016) also describes the role of elite universities in stimulating private tutoring,

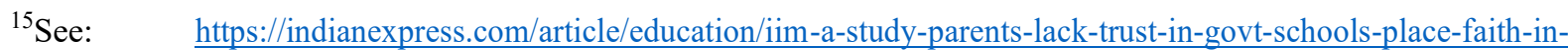
tuition-teachers-5736589/
} 
a factor motivating our analytical approach:

The post-secondary institutions and programs remain highly stratified, with some offering much greater rewards (such as Indian Institute of Technology or All India Institute of Medical Sciences), hence demand for private supplementary tutoring during the years of senior secondary schooling remains intense. With the massive expansion of elementary education over time, the growth in number of seats in these premier institutions has not kept pace with the growth in number of students seeking admission in these institutes, resulting in much fiercer competition for the limited seats." (p 749)

The hierarchical structuring of education system leads to linkages between primary, middle and secondary education. The students' performance at the transition points, grade 5 at primary level and grade 8 at middle level, becomes critical and assessments of performance at these points act as gatekeepers to access secondary education (Jha et al. (2019)). Given this, parents' beliefs of the necessity of private tutoring at primary and middle levels dovetails with the desire to score higher marks in the high-stakes examinations at the secondary level. Thus, the perceived necessity of private tutoring permeates Indian primary and middle levels as well.

The private, for-fee nature of this tutoring has obvious implications for the distribution of access. Azam (2016) reports that for 2007/08, the private tuition expenditure averaged 16.5 percent of per capita consumption, and this rose to 28.5 percent at senior secondary level. Thus, it is not surprising to find that at the secondary level, only 21.6 percent of students in the poorest quintile purchased private tutoring while 38.8 percent of students in the top quintile did. This compositional aspect of private tutoring in India underscores its potential for nullifying portions of the impact on educational equity from the provision of greater access to schooling.

\section{Analytical Approach and Identification}

Our focus is the relationship between RTE and increased private tutoring. While RTE was designed to expand free education to cover all primary students, private tutoring serves the interests of those who are willing and able to pay for the added education and potentially insulates them from educational competition. But just seeing an 
increase in private tutoring after introduction of RTE does not establish that RTE caused the expansion. The main identification challenge arises from the universal implementation of RTE across all states in India. Any change in private tutoring may simply be a reflection of broader trends owing to other causes and not necessarily an impact of RTE. For example, Pratham, a nongovernment organization, began publicizing the results of a broad voluntary testing program of rural youth in $2005 .{ }^{16}$ This annual program, the Annual Status of Education Report (ASER), has continued until the present and has indicated some severe learning deficiencies that call for remediation. Increased private tutoring could simply reflect attempts to make up for problems of inadequate school quality as indicated by the ASER data and other information on the state of Indian schools. ${ }^{17}$

The potential impact of RTE on demand for private tutoring becomes clearer when remedial demands are distinguished from enhancement/competitive demands. The Indian tuition centers serve to improve the grades/scores attained by students - either to bring them up to expectations for their cohort or to enhance the competitiveness of the student for admission to a higher quality institution of higher education (Azam (2016), Ghosh and Bray (2018), Bray (2017)). Concerns about overall quality of schools, which might be heightened by the general expansion of schooling under RTE, will be felt broadly across all parts of the society. On the remedial margin, it is difficult to disentangle any causal impact of RTE from impacts due to other reasons unrelated to RTE. On the other hand, the expansion of the school population with a less than proportionate expansion of upper level and elite school openings will be more salient for high demand households and for households that perceive greater competition for advanced high quality education.

On the enhancement/competition margin, there is a clearer way to see the causal impact of RTE on private tutoring. As Ghosh and Bray (2018) describe, the force of credentialism and competition is strong across broad income groups in India. An increase in access to schooling would be expected to have a larger impact in areas where competition within cohorts for grades and for school entry is already high. A simple model of choice for private tutoring indicates that

\footnotetext{
${ }^{16}$ See http://www.asercentre.org/p/158.html [accessed November 9, 2020].

${ }^{17}$ These findings have to be considered with a caveat since ASER captures only the rural population, therefore may not be representative of the entire country.
} 
high-demand households will have greater use of private tutoring than low-demand households (Dang and Rogers (2008)) and that this demand will expand with increased school enrolment (Kim and Lee (2010)). These forces are amplified in a system that is heavily biased toward sorting and selection (Muralidharan (2019)). In other words, the increase in number of students resulting from RTE increases competition to gain admission in more advanced secondary schools, which the high-demand households perceive as providing a pathway for admission to prestigious institutions of higher education. This increased competition will lead high-demand households to seek private tutoring to supplement formal schooling.

Our key to the identification of the causal effect of RTE on private tutoring is comparing changes in private tutoring in areas already having intense educational competition to changes in areas with less competitive pressures. Extensive U.S. analyses show that the geographical patterns of school attainment are highly influenced by the proximity of higher education institutions, ${ }^{18}$ and these results are in line with the anecdotal evidence for India cited previously. Our main analysis leverages this intuition and defines highly competitive districts as those containing one of the premier technical schools, i.e., an Indian Institute of Technology (IIT). ${ }^{19}$ The location and governance of the original IITs were exogenously set in 1961 according to the IIT Act. ${ }^{20}$ The admissions competition for these undergraduate schools is especially intense as they have been traditionally viewed as a clear gateway to economic success in India. The comparison less-competitive districts are those lacking one of these institutions. ${ }^{21}$ As previously noted, while students from throughout India can attend any given IIT, the importance and competition clearly rises in the local district.

We make use of this heterogeneity in competitiveness at the district level to analyze a difference-in-differences model of expansion of private tutoring caused by the introduction of RTE. Consider $T_{d t}$, the number of new tuition centers per billion in district $\mathrm{d}$ and month $\mathrm{t}$ :

$$
T_{d t}=\alpha_{0}+\alpha_{1} R T E_{t}+\alpha_{2} C_{d}+\beta\left(R T E_{t} \times C_{d}\right)+\gamma Z_{d t}+\varepsilon_{d t}
$$

\footnotetext{
${ }^{18}$ Beginning with Card (1993) and continuing through Carneiro, Heckman, and Vytlacil (2011), Doyle and Skinner (2016), and many other studies, distance to the nearest college or some related measure are used to instrument school attainment in analyses of the returns to schooling.

${ }^{19}$ Indian Institute of Technology (IIT). See https://en.wikipedia.org/wiki/Indian_Institutes_of_Technology.

${ }^{20}$ While there are currently 23 IITs, we only consider the 13 that were establishè before RTE was enacted.

${ }^{21}$ As we discuss below, while we believe this definition of competitiveness provides the clearest treatment group, our results hold when we expand the definition to include other arguably competitive districts.
} 
Where $R T E_{t}=1$ for all months from August 2009 (its date of enactment) through March 2015 and $R T E_{t}=0$ for all months before August 2009; $C_{d}$ is an indicator for competitive districts that have an IIT; $Z_{d t}$ is a vector of time-varying characteristics of district d; and $\varepsilon_{d t}$ is a stochastic error term. Our interest is $\beta$, the coefficient of the marginal impact of being in a competitive district after the enactment of RTE.

The intuition behind this estimation is that, if the educationally-competitive and the less- competitive districts are following common trends in the development of tuition centers, those trends would continue in the absence of RTE. Deviations from trend after the introduction of RTE are interpreted as the causal effect of RTE on private tutoring. In the empirical analysis we can verify and validate the parallel trend assumption for periods prior to enactment of RTE.

Because of the lengthy discussions before adoption of RTE, we must also allow for anticipation effects in the estimation. Specifically, we add an indicator variable for being in a competitive district for either 12 or 24 months prior to enactment of RTE Act in August 2009. Alternatively, we include a 12- or 24-month time trend $(t)$ for the competitive districts.

As noted, states embraced RTE at varying speed. Their passage of enabling legislation stretched from 2009 for a number of years after. Thus, in a parallel set of estimates we define $R T E_{d t}=1$ if $\mathrm{t}$ is at or beyond the state enactment date for the state of district $\mathrm{d}$. This estimation adds cross-sectional variation to the estimation at the cost of potential error in when the idea of expanded access to schools entered into decision making in district $d$.

It is also possible to analyze the impact of RTE on the development of new private schools and new institutions of higher education. These other institutions provide alternative outlets for the expanded educational demand. They do not, however, have the same flexibility as private tutoring centers, and they often involve large capital commitments. An important difference between tutoring firms and these alternative providers of additional education is that the latter (and especially new private schools) are heavily regulated. Thus, the contrast with tutoring involves both the nature of the services provided and the ease with which new firms can enter the market given government regulatory actions.

In the empirical analysis, we also pursue a number of specification tests and extensions. In a robustness analysis, we also investigate a series of alternative ways of 

defining treatment and comparison groups including prior usage of private tutoring and the competitive pressures generated by a broader set of premier tertiary institutions beyond just the IITs.

\section{Data on Educational Firms}

There is no master listing of educational firms in India. We construct a data base of new firm entrants from the official Indian government company registry. In order to operate legally, all firms, including non-profit organizations, must register with the Registrar of Companies (ROC), a component of the Ministry of Corporate Affairs (MCA) of the Government of India (GoI). The overall universe of all the firms that registered during the period 1900-2015 for 35 states and union territories ${ }^{22}$ is available online from the Ministry of Corporate Affairs website. ${ }^{23}$ The universe of all firms electronically available is $1,459,084$, with sufficient information including their principal business activity ${ }^{24}$ and year of registration available for 1,457,281 firms. Appendix Table 2 reports the distribution of firm registrations in India by principal business activity across five time periods: (i) 1900-1950, (ii) 1951-1990, (iii) 1991- 2000, (iv) 2001-2009 and (v) 2011-2015. Firms registered between 1900-1950 constitute only about 1.2 percent of the overall clean sample. ${ }^{25}$ A majority of firm registrations, about 84 percent, took place during the period 1991-2015.

\footnotetext{
${ }^{22}$ The 35 states and union territories include Andaman and Nicobar Islands, Andhra Pradesh, Arunachal Pradesh, Assam, Bihar, Chandigarh, Chhattisgarh, Dadar and Nagar Haveli, Daman and Diu, Delhi, Goa, Gujarat, Haryana, Himachal Pradesh, Jammu and Kashmir, Jharkhand, Karnataka, Kerala, Lakshadweep, Madhya Pradesh, Maharashtra, Manipur, Meghalaya, Mizoram, Nagaland, Odisha, Puducherry, Punjab, Rajasthan, Tamil Nadu, Telangana, Tripura, Uttar Pradesh, Uttarakhand, and West Bengal.

${ }^{23}$ For a recent description of the data, see: https://www.ideasforindia.in/topics/macroeconomics/firm-formation-inindia-the-last-40-years.html and https://blog.theleapjournal.org/2019/03/the-geography-of-firms-and-firm.html [Accessed as on April 21, 2019]. The data reports information on a range of variables including: (a) unique corporate identification number (CIN hereon) - which is used for filing taxation and for other legal purposes in carrying out the business operations, (b) the name of the firm, (c) firm status (whether it is still active, dormant or closed its operations as on 2015 though this information is noisy and it was unclear to us if it was updated dynamically), (d) type of firm - whether it is private or public, (e ) firm category (whether it is limited by shares or limited by guarantees), (f) authorized capital, (g) paid up capital, (h) principal business activity (i) date of registration or incorporation (see footnote below) (j) state/union territory in which the firm was registered and (k) its office address with detailed city, district and pin code (similar to zip code in the USA). We retrieved the data from MCA website during December 2015.

${ }^{24}$ Principal business activity is categorized into (i) Agriculture, (ii) Business, (iii) Community/Social Enterprises, (iv) Construction, (v) Electricity, (vi) Finance, (vii) Insurance, (viii) Manufacturing (food, leather, machinery, metals, papers, wood, textiles, and others), (ix) Mining, (x) Real Estate, (xi) Trading, (xii) Transportation and related services, and (xiii) Others (firms for which this particular information is not provided in the dataset).

${ }^{25}$ The year of registration is the same as year of incorporation of the company. We make use of the term "registered" to refer to both the registration and incorporation of a company in this paper and use it as a measure of firm formation and entry in their respective industries.
} 
We define tuition centers as supplementary tutorial centers that operate outside of school hours. These are companies that offer fee-based classes to teach students concurrently attending elementary or secondary education (including technical/vocational courses offered at the secondary or senior secondary level). Additionally, they offer training for specialized entrance exams to pursue tertiary education. ${ }^{26}$ While three percent are registered as public companies, we refer to them collectively as private tutoring centers.

We define private schools as organizations that are fully substitutable for government schools and provide pre-school, elementary [grade 1 to 8], or secondary education [grade 9 to 12] education. Using the MCA dataset, we captured primarily private schools including international schools (although there was a small number that were not fully private).

Higher education institutions or HEIs are defined as organizations providing tertiary education in science, commerce, and humanities. The broad definition captures institutions providing tertiary professional education such as the Indian Law Institute and the International College of Financial Planning. In addition, we were able to capture private entities that impart specialized education and skill such as taxation offered by Institute of Chartered Tax Advisers of India, music production by Audio Media Private Ltd, pilot training by Star Flight Training Educare Private Limited, and others.

We measure the number of new registrants in each category. This may differ from the overall presence of an entity in the country because of the ability of registered firms to add subsidiaries. For example, Delhi Public School Private Ltd has been franchising since 2007. Its main school is located in Delhi, but franchises are located across 108 districts in India and in 6 countries (UAE, Kuwait, Qatar, Saudi Arabia, Nepal and Singapore). Despite its widespread presence in the country, it appears as one unit in our dataset since the company has to register with Ministry of Corporate Affairs just once, irrespective of its corporate structure.

We use the unique corporate identification number (CIN) to identify the schools, tuition centers, and HEIs. The CIN is a 21-digit code containing information on the listing status, industry code, state code, incorporation year, ownership, and registration number of the firm. We use the industry code in conjunction with the NIC 2004 (national industrial classification of 2004) classification to identify the five-digit codes for education, although

\footnotetext{
${ }^{26}$ India has a variety of admission exams for tertiary education: Indian Institute of Technology Joint Entrance Examinations (IIT JEE) for engineering students, National Eligibility Cum Entrance Test (NEET) for medicine students, and Common Law Admission Test (CLAT).
} 
these codes do not fully identify all schools, tuition centers, or HEIs. We then searched the entire database with key words such as "schools", "tuition", "learning", and "coaching" to identify other industry codes associated with schools or tuition centers. An algorithm that made use of the industry codes and key words jointly was adopted to identify the schools, tuition centers and HEIs from the master data. (Appendix Table 3 gives the details of the industry codes used to identify private tuition centers, schools and HEIs in our sample). Finally, all the identified firms were manually checked to ensure accuracy.

Using this strategy, we identified 868 private tuition centers, 360 private schools, and 3,389 HEIs registered between 1991 and 2015, and located in 374 districts spread. In our final analysis, we considered 171 months of data starting from January 2001 to March 2015, while the 1991-2000 registrations were used subsequently in the robustness analyses. ${ }^{27}$ From each firm's office address, we aggregate the data by district and month of registration.

We obtained population data for each district from the decennial Census surveys conducted in 1991, 2001 and 2011 by the Office of the Registrar General \& Census Commissioner, GoI. We make use of these data points to interpolate linearly district level population information for each month between 1991, 2001 and 2011, and extrapolated for the months between 2011 to March 2015. The district-month population information was then merged with the district-month firm registration database.

The firm registration data have been criticized recently for an incomplete representation of firm formation and their contribution to Indian GDP (Nagaraj (2015), Nagaraj and Srinivasan (2017)), but this remains to date the only source of official data of firm formation in India. Given the critique about the quality of the MCA dataset, we analyzed how many of the registered tuition centers, schools, and HEIs were still operating on June 2019. We made telephone calls and online searches for the 817 tuition centers, 325 schools, and 3,179 HEIs reporting positive investments at the time of registration. ${ }^{28}$ We located 42 percent of tuition centers, 37 percent of schools, and 25 percent of HEIs that were still operating (although it is

\footnotetext{
${ }^{27}$ The registration data are sometimes incomplete. For the definition of educationally competitive districts in the robustness analysis, we consider reported investment of paid-up capital for registrations between 1990-2000, but these data are sometimes missing. We also considered the number of registrations of tuition centers between 19902000, but again these sometimes-lacked data on paid up capital. We are unable to distinguish no effective investment as indicated by no paid-capital from simply missing data. We also fail to identify any unregistered firms that may be illegally operating.

${ }^{28}$ For online searches, we made use of google search engine and other search engines such as justdial, indiamart and sulekha to identify and validate whether an education firm is still operating its unit or not.
} 
likely that some additional institutions might have been operating but simply could not be located). This finding reemphasizes the fact that the MCA dataset contains firms registered in the past. It is suitable for measuring entry, but is not a good source for credibly identifying exits, thus precluding any analysis of the long-term implications of growth in this fee-based shadow education sector.

\section{Basic Results}

The introduction of the Right to Education potentially influences not only the expansion of government schools but also the growth of a variety of private institutions. We focus on tuition centers, the most prevalent of the alternative providers, and we show that their growth is strongly related to the expansion of schooling under RTE. We subsequently return to the other educational providers - private schools and higher education institutions.

\subsection{The growth of tuition centers}

Table 1 provides a description of the flows of new tuition centers in sample 374 districts from 2001-2015. We divide flows between those in less educationally competitive districts (i.e., without an IIT) and those in the 13 educationally competitive districts (with an IIT before RTE). ${ }^{29}$

\section{[Insert Table 1]}

The top row or Table 1 equals the average number of new tuition center per million ${ }^{30}$ that opened in the decade prior to our analysis (1991-2000). ${ }^{31}$ The IIT districts clearly began introducing and using tuition centers before the typical other district. The reasons for this are not clear, although anecdotal discussions with parents, students and households suggest that the

\footnotetext{
${ }^{29}$ Subsequent additions of new IITs brings the total currently available up to 23 . In our preliminary analysis, we observed that the inclusion of New Delhi as part of our competitive districts sample altered the distribution of registration per billion persons such that it no longer represents the distribution as observed with the raw, and absolute, number of registrations. This is primarily due to the relatively small population of New Delhi which generates outliers when the absolute number of registrations are transformed into registrations per billion persons. Therefore, we exclude New Delhi from the analysis even though it has an IIT established in 1961. Nonetheless, from the preliminary analysis, the exclusion or inclusion of New Delhi from our regression analysis does not alter our main findings in any manner.

${ }^{30} \mathrm{We}$ make use of registrations per million persons for our discussion of the descriptive statistics for expositional purposes. For our main estimation results, we make use of registrations per billion persons as it facilitates putting our findings in the national context which has, in total, a population of about one billion. This was the motivating factor to make use of different measures, per million and per billion, for the descriptive and regression analysis respectively.

${ }^{31} \mathrm{We}$ accumulate the registration of new tuition centers over the decade to arrive at an indication of pre-existing differences in educational competition.
} 


\footnotetext{
${ }^{32}$ The alternative of clustering at the state level yields very similar results.
} 
and 2015. The monthly registrations are flat until just before the final enactment of RTE but then show some increase with the anticipation of RTE and a strong jump after enactment in the educationally competitive districts.

\section{[Insert Table 2]}

In Table 2 we consider more formally the monthly introduction of tuition centers across our sample of 374 districts in the period before any potential impact of RTE (20012006). The simplest model (Col. 1) includes just an indicator for competitive districts, a time trend, and the competitive indicator times the time trend. This last term provides a direct test of whether the pre-trends are different. The common trends assumption cannot be rejected.

The other two columns look at variations in this test by adding a state fixed effect and by adding measures of district population and the manufacturing and software share of total company registrations to capture the level of economic activity. Again, there is no significant difference in the trend of tutoring centers between the competitive and less competitive districts before RTE. ${ }^{33}$

\subsubsection{Induced Expansion of Private Tutoring}

The central question is whether introducing the Right to Education alters the demand for private tutoring (as suggested by the raw data in Figure 1). We present the estimates of the basic difference-in-differences model (Eq. 1) in Table 3, using the registration data from January 2001 through March 2015. In the first four columns, we set the introduction of RTE at August 2009 the date of enactment by GoI - and compare the subsequent addition of new tuition centers in the educationally competitive districts with IIT's to that in the other districts of India. The final two columns consider the staggered adoption of implementing legislation across the states and present estimates of the model with state-specific dates for effective introduction.

\section{[Insert Table 3]}

The differential effect of RTE in competitive districts $\left(\beta\left(R T E_{t} \times C_{d}\right)\right.$ in Eq. 1)) gives a direct estimate of the causal impact of RTE on the expansion of private tutoring. The first column provides the simplest estimates that do not allow for any anticipatory effects. Because

\footnotetext{
${ }^{33}$ We also run the test for parallel trends with the entire pre-RTE period between January 2001 and July 2009 (available with authors). The trend differences for tutoring, school and HEIs between competitive and lesscompetitive districts are not statistically significant at the five percent level. At the ten percent level, the common trend assumption is rejected only for HEI registrations per billion persons. Parallel trends are met for both tuition centers and private school registrations per billion persons.
} 
of the history of the politics surrounding the final enactment of RTE, however, we expect some anticipatory development of new tuition centers. Therefore, the remaining columns include terms that allow for some reaction to RTE before its formal ratification in August 2009. This anticipatory effect is included with either dummies for the competitive districts in the 24 months leading up to RTE or by a 24-month time trend for the competitive districts. As seen most easily in Col. 4, the time trend for anticipatory effects is not statistically significant, implying that the anticipatory development in competitive districts is not causing any systematic change in the registration of private tuition centers. All regressions include state fixed effects, and Col. 3 and 4 include the population size of the district and the percentage of firm registrations in manufacturing and software in order to control for the overall development level and demand for skilled labor in the district. The increase in tuition centers within competitive districts is uniformly significant both quantitatively and statistically, ranging between 32 to 37 new tuition centers registrations per billion persons relative to lesscompetitive districts. For our most conservative specification in Col. 4, we see a monthly increase of 35 new tuition centers registrations per billion persons in educationally competitive districts relative to less competitive districts after RTE. Tuition centers vary widely in size, a conservative enrollment estimate of 1,000 students per center implies an expansion of tuition students from 2009-2015 of some 113,250 across the thirteen IIT districts. While India has a wide range of tertiary schools, the IIT's themselves have enrollments less than ten percent this number of total students being tutored. ${ }^{34}$

The final two columns introduce the time-varying implementation and enforcement of the individual states, using state-specific effective starting dates for RTE. These estimates in Col. 5 and 6 again show a strong impact of RTE on the expansion of private tutoring.

In sum, the constitutionally-expanded access through the Right to Education Act induced a strong development of more private tutoring centers in the districts with the most intensive competitive educational pressures. ${ }^{35}$ 6.2.3 Induced Expansion of Other Educational Institutions

\footnotetext{
${ }^{34}$ In 2018, there were 23 IITs with a total of 11,279 students. (https://en.wikipedia.org/wiki/Indian_Institutes_of_Technology, [accessed June 8,2020])

${ }^{35}$ Somewhat anomalously, the post RTE indicator ( $\alpha_{1}$ in Eq. 1$)$ is negative and statistically significant when the staggered adoption of state is considered in col. 5 and 6 . In the case of staggered adoption, the initial spurt in tuition center registrations between 2009-2012 is not captured by the timing of RTE adoption in a majority of the states.
} 
The private tuition centers are the most responsive to altered educational competition, but other avenues of expansion exist. The other margins include private schools and higher education institutions.

There has been a continued expansion in private schooling in India (Kingdon (2017)), but there is not a clear explanation of the varying causes of this expansion. Undoubtedly, this trend is motivated in part by concerns about the overall quality of the government schools. Our data permit investigating whether RTE also contributed to the expansion of private schools. For this, however, we can only consider registered private school, a heavily regulated subset of all private schools in India.

Similarly, another point of impact could be the further development of higher education institutions (HEIs). These institutions are aimed at a group of students older than those directly affected by RTE. But, RTE potentially expands the number of students prepared for the wide variety of HEI programs, which often include specialized vocational courses that can be taken in conjunction with the regular schools.

\section{[Insert Figure 2]}

A parallel analysis to that of tuition centers shows a generally positive response of these other educational institutions to RTE. Figure 2 shows systematic response in the raw data of these other institutions to the introduction of RTE when we compare the IIT districts and the other, less competitive districts.

\section{[Insert Table 4]}

The systematic impact of RTE on the expansion of these institutions holds when we reproduce the prior analysis for private schools and HEIs. To establish the basis for the difference-in-differences analysis, Table 4 provides evidence on the parallel trends assumption of these new investments, again comparing the educationally competitive IIT districts to all others. There is no significant difference in registrations between the two sets of districts in the lead up to RTE (2001-2006) for either private schools (Col. 1-2) or HEIs (Col. 3 - 4).

The newly induced investment in schools and HEIs in the highly-competitive districts are seen in Table 5 where we present the causal estimates of the impact of RTE. With the alternative specifications of any anticipatory effects and of other district factors and with the state-specific start dates, the response of new investments in private schools (Col. 12) is positive and statistically significant ranging between 10-12 new school registrations per 
billion district population. The results for the staggered adoption of RTE by states is slightly weaker but still shows an impact on new investments in private schools. We observe similar pattern for HEI (Col 4-6), although the statistical significance dissipates with the use of staggered adoption of RTE by states.

\section{[Insert Table 5]}

The responsiveness of these other educational institutions is somewhat surprising, but it reinforces the threat of countervailing forces to achieving more equitable outcomes from RTE. The approval process and regulatory structure surrounding these institutions is much more elaborate than that for tuition centers, yet these new registrations have navigated through the hurdles. Particularly with respect to the increased private schools, individual behavior of better off families is potentially offsetting the general improvement in access due to RTE. Moreover, these results quite likely underestimate the total induced demand because we lack data on unregistered private schools. While the RTE Act made unregistered schools illegal, there is little evidence that this was closely enforced.

\section{Robustness of Results}

The previous analysis focused on the 13 educationally competitive districts defined by having an IIT established before RTE in 2009. While we believe this provides the clearest comparison sets, it is important to ensure that the prior findings were not driven by the definition of competitive districts. We can validate the overall finding of induced private tutoring by introducing five other credible methods of identifying educationally competitive districts. These fall into two broad extensions - one based on refinements of the existence of higher education institutions in the district and one based on historical supplementary educational investments.

\subsection{Alternative Definitions of Educationally Competitive Districts}

The IITs are India's premier engineering institutions, and admission to one is extremely competitive. In 2018, there were less than 12,000 students across the IITs. ${ }^{36}$ The number of such institutions has expanded over time, reaching a total of 23 in 2016, but we focused on those established prior to RTE to avoid any possible endogeneity arising from site selection. It is still possible, however, that districts with IITs established closer to the passage of RTE are found in districts that have other characteristics that relate to educational demand, to the nature

\footnotetext{
${ }^{36} \mathrm{https} / / /$ en.wikipedia.org/wiki/Indian_Institutes_of_Technology [Accessed May 20, 2020]
} 
of RTE implementation, or to other important characteristics. To circumvent this possibility, we consider alternative treatment groups.

The most stringent approach is to look just at the six IITs that were in existence before 2001, the start of our analytic period and prior to the discussions leading to the RTE Act. This restriction is, however, potentially offset by the small sample of resultant competitive districts that limits the power in the analysis.

We create two additional groupings of educationally competitive districts by merging information on districts with Institutes of National Importance (INIs) with districts with IITs. INIs come from a broader set of institutions that expands the educational focus to include medicine, management, architecture, management, information technology, and more. These are also very selective institutions identified at varying times and regularly updated by the Ministry of Human Resource and Development (MHRD), Government of India. ${ }^{37}$

One alternative defines educationally competitive districts as those which had a premier INI institution established before 2001 but also within the full set of 13 IIT districts. This condition, below referred to as "IIT and premier institution established before 2001" adds back three districts, leaving a sample of nine districts competitive districts. As a third alternative, we define competitive districts as those in which either an IIT or an INI school was established before 2001 - referred as "Premier institution established before 2001". For this group, we identify 39 districts as competitive districts.

A different approach to defining educationally competitive districts relies on early use of private supplementary education across India. Returning to the data base on private educational investments, we use two additional ways of defining competitive districts. First, we define any district that had new registrations for tuition centers, private school or higher education institutions for the period 1991-2000 as showing prior competitiveness. We find 89 such districts. ${ }^{38}$ Second, we expand on this to identify any district in the prior period that had recorded investments at registration (measured by paid-up capital) in either tuition centers, schools, or higher education institutions. This definition of competitiveness yields 82 districts. ${ }^{39}$

\footnotetext{
${ }^{37}$ https://en.wikipedia.org/wiki/Institutes_of_National_Importance [accessed May 20, 2020]

${ }^{38}$ Only three districts (Gandhi Nagar, Hardwar, and Medinipur) are categorized as competitive districts on the basis of an IIT but do not fall under competitive districts on the basis of prior number of centers and investments.

${ }^{39}$ Not all registrants report the amount of paid-up capital at registration. Thus, this could simply reflect missing data,
} 
When we replicate our basic investment analysis for these expanded collections of treated competitive districts, we find consistent and often larger impacts of RTE. With each alternative set of competitive districts, we can confirm parallel trends in registrations of tuition centers, private schools, and HEIs over the period 2001-2006 (see Appendix Tables 5- 19). Based on this, we turn to the impact of RTE.

\section{[Insert Table 6]}

Table 6 summarizes the causal impact of RTE on registrations of private education (both tutoring and private schools) across the different comparison groups. This table shows just the differential impact of RTE across the five alternative samples, while the full estimation results can be found in Appendix Tables 20-34. The rows reproduce the estimate from Table 3, col. 3 and 5 for tuition centers and the parallel specifications for private schools and HEIs in Table 5. The first three columns relate to the national enactment of RTE in 2009, and the latter three looks at state implementation dates. Each table entry comes from a separate underlying regression estimate.

Except for estimates from the highly-restricted six-district sample of having an IIT before 2001, the results across educational response categories in col. 1-3 are uniformly significant at the five percent level or better. And, with a few anomalies, the estimates in col. 4-6 that are based on state policy timing are also strongly positive and significant.

Interestingly, the impact of RTE on private schooling appears even stronger when the competitive districts are defined by presence of premier institutions, prior registrations, and investments. It appears that RTE, with its potential negative influence on overall school quality, increases the demand for private schools. Still, the rate of new registrations for tuition centers remains much greater than that for private schools. While possibly related to the scale of operations of the two, there is prima facie evidence against that argument: The average size of two institutions is not very different if viewed by the average paid up capital at registration. Again, however, these are just the registered private schools, which almost certainly understate the total increase in private schools.

The overall impact of RTE on the development of new HEIs also appears significant. The magnitude of the impact is somewhat surprising, since across the samples the new registrations of HEIs appears greater than those of tutoring centers. However, as discussed

or it could reflect that some registrants are not really prepared to begin operation at the time of registration. 

scale of operation of HEIs is much different from that of tuition centers. The average size of HEI is almost four times the average size of tuition centers.

The consistency of results with these alternative definitions of educationally competitive districts makes it clear that the finding of a direct impact of RTE on private supplemental education is not an artifact of the specific comparison groups. There is strong support for a conclusion that RTE led to offsetting schooling choices that dampened any enhanced equity of access under RTE.

\subsection{Incorporating District Size}

The prior models analyzed the per capita development of new institutions and also included a measure of district population. The measurement of population does, however, include some inaccuracies because it is necessary to interpolate population by district in our monthly registrations. One concern is that the inaccuracies in population size could distort the estimated responsiveness to RTE. Additionally, it might be that district size, by affecting the relevant market size, directly affects market entry.

As an alternative, we look at the absolute number of new tuition centers (and schools and HEIs) and then control for district population size. The parallel trend assumption again is not rejected for new tuition, private school and HEI registrations across different definitions of competitive districts, with the exception of private school and HEI registrations under the definition of any prior registrations and investments (see Appendix Table 35 and Appendix Figure 1). The estimates based on total number of new tuition center registrations, however, are qualitatively similar to our prior estimates (see Appendix Table 36). The impact of RTE in competitive districts remains strong and significant. Further, we find that the absolute number of school and HEI registrations have also increased in competitive districts, statistically significant at 5 percent except for the stringent definition as having IIT established before 2001. 8 Evidence on Educationally Competitive Motivations

If the increase in private tutoring is predominantly remedial in nature, concerns about private tutoring's inequitable aspects may be lessened because it is acting to remove deficiencies that would otherwise detract from successful human capital development. The competitive side 
of private tutoring, however, tends to be examination-focused with the objective of ensuring positions in the most rewarding schools and programs - and with the more advantaged insulating themselves from competition of the predominantly less advantaged students covered by RTE.

We provide two types of evidence that the surges in private tutoring and private school registrations previously observed are weighted toward competitive motives. First, the largest increases in private tutoring registrations were not found in districts requiring the quickest adjustment to new demands. Second, the pattern of increases follows existing concentrations of more educated families who have the means and the competitive inclinations to expand both private tutoring and private schooling.

\subsection{Adjustments to the Implementation of RTE}

The implementation of RTE led to an influx of new students in both government and private schools. This, in turn, put heavier demands on facilities, on class sizes, and on the quality of teaching provided by government and private schools. While ostensibly governed by the quality provisions of RTE, unless the existing and new school entrants are able to expand sufficiently to meet this demand, there would be an increase in remedial demand for private tutoring from households.

We do not have an ideal way of testing the magnitude of adjustment pressures, but we can look at the uneven adoption of RTE across states to make preliminary inferences. Specifically, it is plausible that the private reactions of households seeking remedial measures would be stronger in states which were first to adopt RTE relative to late adopters. Early-adopting states had less time to support quality standards relative to schools in the late-adopting states. Therefore, we would expect remedial demands to lead to greater expansion of tuition centers in early-adopting states relative to late-adopting states.

While we cannot conclusively show that the timing of adoption of RTE by states is random, anecdotal evidence indicates that a state's decision to adopt RTE early or late was not influenced by their ability and capacity to implement its provisions better. To illustrate, both Tamil Nadu (late-adopter) and Maharashtra (early-adopter) were found to have better roadmaps for RTE implementation (Sarin et al. (2015)). In addition, an examination of the timing of adoption by each state reveals no obvious pattern supporting systematic adoption (see Appendix Table 1).

If state adoption is random, assessing adoption of private tutoring across early and late 

state-adopters of RTE is informative about the underlying motivations for expansion of private tutoring and private schooling. Given this perspective, we replicate our primary model found in Equation (1) where we define the early-adopting states as those which had adopted RTE on or before 2010 and late-adopting states as those which adopted RTE later than 2010. We categorized nine early-adopting states (123 districts) as treated states, and we categorize 20 lateadopting states (251 districts) as comparison states.

The hypothesis of parallel trends in registrations of tuition centers per billion person is not rejected for the comparison of early- and late-adopting states over the pre-RTE period (20012006). In comparing increases in private tutoring registrations, we include anticipatory effects as before, but they are not statistically significant.

The differential implementation pressures across states do not appear to lead to significant remedial demands for private schooling. Defining states that were early adopters of $\mathrm{RTE}$ as $E_{\mathrm{d}}$, the difference-in-difference estimate $\left(\beta \bullet R T E_{t} \times E_{d}\right)$ indicates that the registration of tuition centers per billion persons is actually smaller among districts in early-adopting states relative to late-adopting states (Appendix Table 37) and is statistical insignificant. This pattern holds true when we estimate the model with absolute number of tuition center registrations as the dependent variable (not reported here). These results are thus consistent with a conclusion that the change in the registration of tuition centers in response to introduction of RTE is not being driven primarily by remedial motives.

\subsection{More Direct Demand Information}

The India Human Development Survey (IHDS) provides richer details about the changing educational patterns of households in the competitive and less-competitive districts. ${ }^{40}$ The IHDS is comprised of two nationally representative and multi-topic household survey administrations conducted in 2004-2005 and 2011-2012 and permits a deeper look into pre- and post-RTE comparisons. We are able to match 97 percent of districts in our MCA dataset with data in the IHDS surveys. We focus our descriptive analysis on the educationally competitive districts defined on the basis of IIT established before RTE. ${ }^{41}$

\footnotetext{
${ }^{40}$ The description of the surveys and access to the data can be found at https://ihds.umd.edu/data. See also Desai and Vanneman (2018).

${ }^{41}$ The overall findings discussed below hold true across alternative definitions of competitive districts with the exception of private tuition take-up under the competitive definitions based on prior registrations and prior investments.
} 
Our educationally competitive districts are meant to identify the presence of higher numbers of high-demand households relative to the composition in less-competitive districts. The extant literature, while subject to some controversy, shows the role of parents and other adult members' education in creating aspirations for the children's educational pursuits. ${ }^{42}$ Thus, when we measure the education-demand of a household in the IHDS by the highest education level completed by any adult in the household, we expect to find more educationally accomplished households situated in competitive districts when compared to those in less-competitive districts. This is the case both before and after RTE enactment; Appendix Table 39 shows that there is higher probability of an adult who has completed secondary schooling and above in educationally competitive districts relative to less-competitive districts. The differential is particularly large for females in the household.

\section{[Insert Table 7]}

When we move to consideration of schooling patterns, we find general confirmation of our interpretation of the prior registration data. The enactment of RTE guaranteed increased access to schooling for existing and new students. Consequently, student enrolment increased in both government and private schools, especially at the elementary level, but this increase was accompanied by substantial shifts from government to private schools. Table 7 shows how the shares of students in government and private schools changed after the RTE enactment in both competitive and less-competitive districts. While the share of students attending private schools increased in both educationally-competitive and less-competitive districts, the movement was significantly larger in competitive districts at both the primary and the upper primary levels. This reaction, particularly in the educationally competitive districts, is entirely consistent with the general perception that private schools provide better education and instill aspirations to pursue more educational outcomes among students in comparison to government schools.

\section{[Insert Table 8]}

The IHDS data also allow us to trace changes in both government and private school students in patterns of private tutoring and to compare the movement to private supplementation

\footnotetext{
${ }^{42}$ There is a uniformly positive correlation between parental education and children's education, but the causal structure is not well-understood (see, for example, Sewell and Shah (1968), Black, Devereux, and Salvanes (2005), Kajisa and Palanichamy (2010), Ermisch and Pronzato (2010), and the review in Holmlund, Lindahl, and Plug (2011)). For our purposes, the exact causal structure of family inputs is not crucial, as long as the correlates of parental education also point to high demand.
} 
between educationally competitive and less competitive districts. Over the period of RTE enactment, enrollment in private tutoring increased in educationally competitive districts relative to less-competitive districts for both primary and upper-primary students (Table 8). With the exception of private school students in less competitive districts, there is a uniform increase in private tutoring at primary and at upper primary levels between 2005 and 2012. At both schooling levels and across government and private schools, the increases in private tutoring are skewed toward students in the educationally competitive districts.

Another aspect of the increase in private tutoring after RTE that is consistent with the emphasis of the competitive margin is the higher increase in private tuition take-up by students attending upper-primary level in comparison to those attending primary level. The upper-primary level marks the first transition from mass to specialized education, and it is the first step in determining the trajectory of education and occupation outcomes (Jha et al. (2019).

While the results with the more detailed survey data are descriptive and cannot be given a causal interpretation, they are all consistent with the hypothesis that the observed surges in private tutoring identified previously reflect competitive motivations. As such, there are clear concerns that the private reactions of families to increased school access through RTE are offsetting the beneficial effects of RTE on educational equity.

\section{IHDS data on achievement}

The overall impact of RTE, nonetheless, depends on how good the tuition centers are at improving the skills of students. Previous analyses of private tutoring provide a general prima facie case that there can be clear educational advantages to tuition centers (e.g., Banerjee, Cole, Duflo, and Linden (2007), Muralidharan, Singh, and Ganimian (2019)), but those centers induced to start by RTE may still be different and may be unable to get these experimental gains.

The IHDS data on student learning provides a partial, but incomplete picture of the quality impact of tuition centers. The IHDS data on performance provides a glimpse into the learning in India, but it is confined to only the first and second child belonging to the agegroup of 8-11 years old. These data can provide a description of how learning has changed in educationally competitive and less competitive districts and of how this relates to private tutoring.

[Insert Table 9] 
The performance of first and second child in the pre-RTE period (2004-2005) can be directly compared to that of a similar cohort in the post- RTE period (2011-2012). Table 9 breaks the average performance in reading, math, and writing ability performance into that for students attending tuition centers and that for those who did not. Interestingly, we find that the average score in reading and writing ability for those attending tuition centers in competitive districts has increased dramatically by 16.30 and 5.16 relative to less-competitive districts after RTE enactment. Most importantly, the increase in average score in reading and writing ability for those attending private tuition is statistically different than those not attending private tuition.

The same is not true in terms of the ability to carry out mathematical exercises where the change in average performance is not statistically different between tuition attending and notattending children in educationally competitive relative to less-competitive districts. The overall finding remains true for alternative definitions of competitive districts with the exception of definition on the basis of prior registrations and investments (see Appendix Table 43). While for obvious reasons these comparisons should not be over-interpreted, they are consistent with a conclusion that attendance at a tuition center leads to a competitive advantage - and that this will generally work to the detriment of those helped on the margin through RTE-induced access.

\section{Conclusions}

There is a long history of policy initiatives designed to expand access to schools in developing countries. Perhaps the most well-known is the "Education for All" initiative. This international initiative became central to policy discussions of UNESCO and the World Bank and was an essential element of the parallel education plank of the Millennium Development Goals of the United Nations. ${ }^{43}$ These initiatives, catalyzed at international meetings beginning in 1990, were built on the overwhelming evidence of inequities around the world in access to schools and thus in limitations on future opportunities for wide swaths of the population to participate effectively in modern society. While there have been critiques of these movements based on quality aspects of expanded schools, there is no doubt that the sentiments behind them are well founded. ${ }^{44}$

This analysis of the 2009 constitutional mandate of a Right to Education in India

\footnotetext{
${ }^{43}$ See, for example, UNESCO (2000b).

${ }^{44}$ Hanushek and Woessmann (2015a)
} 
suggests that providing access by itself may not effectively deal with the educational inequities. The Right to Education Act provided that all Indian children should be provided a free education meeting certain input-quality standards through age 14 . On the surface this appears to open up the education system to disadvantaged students who were previously underserved and to further equity consistent with Education for All.

At the same time, the Indian education system is very competitive for those who wish to go further in schooling. It is especially competitive to gain admission into one of the Indian Institutes of Technology (IIT), the premier undergraduate institutions in India. Adding more students to this competition through RTE in fact increases the stakes for students interested in enrolling in top schools. This intense competition has fueled a private tutoring sector that can help provide individuals with a competitive advantage for college admission.

When we trace registrations of new tuition centers across India, we find that they increase sharply with the introduction of RTE. Importantly, registrations are heavily skewed toward districts already having significant educational competition. Specifically, the introduction of RTE leads to substantial increases in tuition centers in districts that have an IIT compared to districts that do not have an IIT.

By comparing reactions to RTE in districts that are highly-competitive for further education with those that have long been less educationally competitive, we obtain causal estimates of a significant independent impact of RTE on private tutoring. Changes in defining competitive districts - to those either with very early prior expansion of tuition centers, with early capital investment in private educational institutions, or with other premier institutes of national importance - does not change the conclusions about the direct impact of RTE on the expansion of private tutoring. These estimates are robust to a variety of model specifications and alternative comparison groups.

Because the tuition centers charge fees that exclude the most disadvantaged, their clientele comes from higher up the income distribution. As a result, the tuition centers tend to reinforce existing inequities in access to education beyond the compulsory portion. In other words, opening up of access to primary and lower secondary schooling can induce private market responses that may inhibit further schooling opportunities for the newly enfranchised, and thus may thwart the government attempts to expand overall educational opportunities. 
Interestingly, in the debates in the legislature leading up to the Right to Education Act, there is no mention of tuition centers (the Indian term for private tutoring centers). The thought that RTE might also induce growth in private centers and thus reinforce some existing inequities does not appear to have been considered.

The limited evidence on student outcomes after RTE is not very encouraging. It suggests that aggregate performance has declined, a fact that might be forecast from bringing new, previously not engaged students into a schooling sector that is stretched by large enrollment increases. But the available evidence also suggests that attending private tutoring has on average been associated with better outcomes.

It is not possible to ascertain the net effect of RTE, where expansion of access to schooling is balanced by the disequalizing effect of induced private supplementation. But clearly, the design of such government programs that have at their heart strong distributional objectives must also consider private reactions that might limit program effectiveness. Interestingly, writing before RTE, Amartya Sen (2009) concluded that private tutoring "effectively negates the basic right of all children to receive elementary education and replaces it by seeing effective education as a privilege, reserved for the better placed in society." He did not consider the possibility that governmental policies to open access to schooling could actually exacerbate the inequities of private tutoring. 


\section{References}

Azam, Mehtabul. 2016. "Private Tutoring: Evidence from India." Review of Development Economics 20, no. 4: 739-761.

Banerjee, Abhijit V., Shawn Cole, Esther Duflo, and Leigh Linden. 2007. "Remedying Education: Evidence from Two Randomized Experiments in India." The Quarterly Journal of Economics 122, no. 3 (August): 1235-1264.

Bhorkar, Shalini, and Mark Bray. 2018. "The expansion and roles of private tutoring in India: From supplementation to supplantation." International Journal of Educational Development 62(September): 148-156.

Black, Sandra E., Paul J. Devereux, and Kjell G. Salvanes. 2005. "Why the apple doesn't fall far: Understanding intergenerational transmission of human capital." American Economic Review 95, no. 1 (March): 437-449.

Bray, Mark. 1999. The shadow education system: Private tutoring and its implications for planners, 61. Paris: UNESCO.

Bray, Mark. 2017. "Schooling and Its Supplements: Changing Global Patterns and Implications for Comparative Education." Comparative Education Review 61, no. 3: 469-491.

Bray, Mark, Magda Nutsa Kobakhidze, and Larry E. Suter. 2020. "The Challenges of Measuring OutsideSchool-Time Educational Activities: Experiences and Lessons from the Programme for International Student Assessment (PISA)." Comparative Education Review 64, no. 1: 87-106.

Card, David. 1993. "Using Geographic Variation in College Proximity to Estimate the Return to Schooling." National Bureau of Economic Research Working Paper Series No. 4483.

Carneiro, Pedro, James J. Heckman, and Edward J. Vytlacil. 2011. "Estimating marginal returns to education." American Economic Review 101, no. 6 (October): 2754-2781.

Dang, Hai-Anh, and F. Halsey Rogers. 2008. "The Growing Phenomenon of Private Tutoring: Does It Deepen Human Capital, Widen Inequalities, or Waste Resources?" The World Bank Research Observer 23, no. 2: 161-200.

Das, Jishnu, and Tristan Zajonc. 2010. "India shining and Bharat drowning: Comparing two Indian states to the worldwide distribution in mathematics achievement." Journal of Development Economics 92, no. 2 (July): 175-187.

Desai, Sonalde, and Reeve Vanneman. 2018. India Human Development Survey-II (IHDS-II), 2011-12: Inter-university Consortium for Political and Social Research [distributor].

Doyle, William R., and Benjamin T. Skinner. 2016. "Estimating the education-earnings equation using geographic variation." Economics of Education Review 53(August): 254-267.

Ermisch, John, and Chiara Pronzato. 2010. "Causal Effects of Parents' Education on Children's Education." Institute for Social and Economic Research No. 2010-16. University of Essex (February).

Ghosh, Pubali, and Mark Bray. 2018. "Credentialism and demand for private supplementary tutoring: A comparative study of students following two examination boards in India." International Journal of Comparative Education and Development 20, no. 1: 33-50.

Government of India. 2016. Education in India. NSS 71st Round. New Dehli: National Sample Survey Office.

Hanushek, Eric A., and Ludger Woessmann. 2015a. The knowledge capital of nations: Education and the economics of growth. Cambridge, MA: MIT Press.

Hanushek, Eric A., and Ludger Woessmann. 2015b. Universal basic skills: What countries stand to gain. Paris: Organisation for Economic Co-operation and Development.

Holmlund, Helena, Mikael Lindahl, and Erik Plug. 2011. "The causal effect of parents' schooling on children's schooling: A comparison of estimation methods." Journal of Economic Literature 49, no. 3: 615-651.

Jayachandran, Seema. 2014. "Incentives to teach badly: After-school tutoring in developing countries." Journal of Development Economics 108(May): 190-205. 
Jha, Jyotsna, Neha Ghatak, Shreekanth Mahendiran, and Shubhashansha Bakshi. 2013. "Implementing the Right to Education Act 2009: the Real Challenges." Discussion Paper Bangalore, India: Centre for Budget and Policy Studies (February).

Jha, Jyotsna, Neha Ghatak, Puja Minni, Shobita Rajagopal, and Shreekanth Mahendiran. 2019. Open and Distance Learning in Secondary School Education in India: Potentials and Limitations: Routledge - Taylor and Francis.

Kajisa, Kei, and N. Venkatesa Palanichamy. 2010. "Schooling Investments over Three Decades in Rural Tamil Nadu, India: Changing Effects of Income, Gender, and Adult Family Members' Education." World Development 38, no. 3 (March): 298-314.

Kim, Sunwoong, and Ju- Ho Lee. 2010. "Private Tutoring and Demand for Education in South Korea." Economic Development and Cultural Change 58, no. 2 (January): 259-296.

Kim, Young Chun, and Jung-Hoon Jung. 2019. Shadow education as worldwide curriculum studies. Cham, Switzerland: Palgrave Macmillan.

Kingdon, Geeta G. 2017. "The Private Schooling Phenomenon in India: A Review." IZA DIscussion Paper No. 10612. Bonn: IZA (March).

Kobakidze, Magda Nutsa, and Larry E. Suter. 2020. "The global diversity of shadow education." European Journal of Education 55, no. 3 (September): 316-321.

Muralidharan, Karthik. 2019. "Reforming the Indian School Education System." In What The Economy Needs Now, edited by Abhijit Banerjee, Gita Gopinath, Raghuram Rajan, and Mihir S. Sharma. New Delhi: Juggernaut Books.

Muralidharan, Karthik, Abhijeet Singh, and Alejandro J. Ganimian. 2019. "Disrupting Education? Experimental Evidence on Technology-Aided Instruction in India." American Economic Review 109, no. 4 (April): 1426-60.

Nagaraj, R. 2015. "Size and Structure of India's Private Corporate Sector: Implications for the New GDP Series." Economic \& Political Weekly 50, no. 45 (November 7): 41-47.

Nagaraj, R., and T.N. Srinivasan. 2017. "Measuring India's GDP growth: Unpacking the Analytics \& Data Issues behind a Controversy that Refuses to Go Away." In India Policy Forum 2016-17, edited by Shekhar Shah, Barry Bosworth, and Karthik Muralidharan. Los Angeles: Sage: 73-128.

Park, Hyunjoon, Claudia Buchmann, Jaesung Choi, and Joseph J. Merry. 2016. "Learning Beyond the School Walls: Trends and Implications." Annual Review of Sociology 42, no. 1: 231-252.

Pratichi Research Team. 2009. The Pratichi Education Report II -- Primary Education in West Bengal: Changes and Challenges. Dehli, India: Pratichi (India) Trust (December).

Rangaraju, Baladevan, James Tooley, and Pauline Dixon. 2012. The Private School Revolution in Bihar: Findings from a survey in Patna Urban. New Dehli: India Institute.

Sachdeva, Suman, Seema Rajput, Anandini Dar, Annie Namala, Sanjeev Rai, Sreedhar Mether, Resmi Bhaskaran, Ravi Prakash, Vinay Kantha, Radhika Alkazi, Niranjan Aradhya, Shireen Vakil Miller, Ajay Kumar Sinha, Alex George, and Anjela Taneja. 2015. Status of Implementation of the Right of Children to Free and Compulsory Education Act, 2009: Year Five (2014-15). New Dehli, India: RTE Forum (March).

Sarin, Ankur, Sunaina Kuhn, Bikkrama Daulet Singh, Praveen Khanghta, Ambrish A Dongre, Ekta Joshi, Arghya Sengupta, and Faiza Rahman. 2015. State of the Nation: RTE Section 12(1)(c) Available at SSRN: http://dx.doi.org/10.2139/ssrn.2637817) (July 30).

Sen, Amartya. 2009. "Introduction: Primary schooling in West Bengal." In The Pratichi Education Report II -- Primary Education in West Bengal: Changes and Challenges, edited by Pratichi Research Team. Dehli, India: Pratichi (India) Trust: 9-18.

Sewell, William H., and Vimal P. Shah. 1968. "Parents' Education and Children's Educational Aspirations and Achievements." American Sociological Review 33, no. 2 (April): 191-209.

Shah, Manisha, and Bryce Millett Steinberg. 2019. "The Right to Education Act: Trends in Enrollment, Test Scores, and School Quality." NBER Working Paper No. 25608. Cambridge, MA: National Bureau of Economic Research (February). 
Singh, Abhijeet. 2020. "Learning More with Every Year: School Year Productivity and International Learning Divergence." Journal of the European Economic Association.

Taneja, Anjela, Venkatesh Malur, John Butler, Vinay Kantha, and Randeep Kaur. 2011. Status of Implementation of the Right of Children to Free and Compulsory Education Act, 2009: 1 April 2010-2011 New Dehli, India: RTE Forum.

UNESCO. 2000a. The Dakar Framework for Action. Paris: UNESCO.

UNESCO. 2000b. World Education Report 2000: The right to education -- Towards education for all throughout life. Paris: UNESCO.

UNESCO. 2003. Global Education Digest, 2003: Comparing Education Statistics Across the World. Montreal: UNESCO Institute for Statistics.

Zhang, Wei, and Mark Bray. 2020. "Comparative research on shadow education: Achievements, challenges, and the agenda ahead." European Journal of Education 55, no. 3 (September): 322341. 
Table 1: Average flow of new tuition centers registrations per million persons

\begin{tabular}{|c|c|c|c|c|}
\hline \multirow{2}{*}{ Year } & \multicolumn{2}{|c|}{ Less-competitive districts } & \multicolumn{2}{|c|}{ Educationally-Competitive districts } \\
\hline & Mean & SE & Mean & SE \\
\hline 1991-2000 (average) & 0.000 & {$[0.000]$} & 0.005 & {$[0.001]$} \\
\hline 2001 & 0.002 & {$[0.001]$} & 0.009 & {$[0.005]$} \\
\hline 2002 & 0.000 & {$[0.000]$} & 0.004 & {$[0.003]$} \\
\hline 2003 & 0.001 & {$[0.001]$} & 0.006 & {$[0.003]$} \\
\hline 2004 & 0.001 & {$[0.000]$} & 0.006 & {$[0.003]$} \\
\hline 2005 & 0.002 & {$[0.001]$} & 0.005 & {$[0.003]$} \\
\hline 2006 & 0.002 & {$[0.001]$} & 0.009 & {$[0.004]$} \\
\hline 2007 & 0.002 & {$[0.001]$} & 0.033 & [0.009] \\
\hline 2008 & 0.003 & {$[0.001]$} & 0.022 & [0.009] \\
\hline 2009 & 0.004 & {$[0.001]$} & 0.035 & [0.009] \\
\hline 2010 & 0.005 & {$[0.001]$} & 0.038 & {$[0.008]$} \\
\hline 2011 & 0.008 & {$[0.001]$} & 0.056 & {$[0.013]$} \\
\hline 2012 & 0.008 & {$[0.001]$} & 0.098 & {$[0.020]$} \\
\hline 2013 & 0.007 & {$[0.001]$} & 0.047 & {$[0.011]$} \\
\hline 2014 & 0.005 & {$[0.001]$} & 0.024 & {$[0.008]$} \\
\hline 2015 & 0.007 & {$[0.002]$} & 0.039 & {$[0.021]$} \\
\hline Number of districts & 361 & - & 13 & - \\
\hline Average pre-RTE & 0.002 & {$[0.000]$} & 0.013 & {$[0.002]$} \\
\hline Average post-RTE & 0.007 & {$[0.000]$} & 0.050 & {$[0.005]$} \\
\hline $\begin{array}{l}\text { Differences between } \\
\text { post-RTE and pre- } \\
\text { RTE }\end{array}$ & $0.005 * * *$ & {$[0.000]$} & $0.037 * * *$ & {$[0.005]$} \\
\hline
\end{tabular}

Note: Competitive districts have an IIT located in them before the enactment of RTE in August 2009 by Government of India. Standard errors are reported in parentheses. We undertook t-test to arrive at the differences of average registrations of tuition centers between pre and post RTE. $* \mathrm{p}<0.10,{ }^{* *} \mathrm{p}<0.05, * * * \mathrm{p}<0.01$. 
Table 2: Testing the parallel trends for new tuition center registrations per billion persons

\begin{tabular}{|l|c|c|c|}
\hline Independent Variables & {$[1]$} & {$[2]$} & {$[3]$} \\
\hline Educationally Competitive District Indicator & 7.242 & 8.305 & 7.810 \\
\cline { 2 - 4 }$\left(C_{d}\right)$ & {$[20.724]$} & {$[20.726]$} & {$[20.795]$} \\
\hline \multirow{2}{*}{ Time Trend $(t)$} & 0.012 & 0.012 & 0.010 \\
\cline { 2 - 4 } & {$[0.011]$} & {$[0.011]$} & {$[0.011]$} \\
\hline \multirow{2}{*}{ Differential trend $\left(t \times C_{d}\right)$} & $\mathbf{- 0 . 0 0 8}$ & $\mathbf{- 0 . 0 0 8}$ & $\mathbf{- 0 . 0 0 9}$ \\
\cline { 2 - 4 } & {$[\mathbf{0 . 0 7 4}]$} & {$[\mathbf{0 . 0 7 4}]$} & {$[\mathbf{0 . 0 7 4}]$} \\
\hline \multirow{3}{*}{ Population } & & & $0.000 * * *$ \\
\hline \multirow{2}{*}{ Share of Manufacturing $[\%]$} & & & {$[0.000]$} \\
\hline \multirow{2}{*}{ Constant } & & & $-0.039 * *$ \\
\hline & & & {$[0.018]$} \\
\hline Observations & -2.105 & -3.536 & -2.640 \\
\hline R-square & {$[3.105]$} & {$[3.259]$} & {$[3.241]$} \\
\hline State fixed effects & 26,928 & 26,928 & 26,928 \\
\hline
\end{tabular}

Note: Dependent variable: number of new tuition centers per billion population monthly in each district. Sample is January 2001 to December 2006. Standard errors clustered at the district level. Competitive districts are those with an IIT established before enactment of RTE in 2009. ${ }^{*} \mathrm{p}<0.10,{ }^{* *} \mathrm{p}<0.05,{ }^{* * *} \mathrm{p}<0.01$. 
Table 3: Effect of RTE on new tuition centers registrations per billion persons

\begin{tabular}{|c|c|c|c|c|c|c|}
\hline \multirow{2}{*}{ Independent Variables } & \multicolumn{4}{|c|}{ RTE $=1$ after August 2009} & \multicolumn{2}{|c|}{$\mathrm{RTE}=1$ after state enactment } \\
\hline & [1] & [2] & [3] & [4] & [5] & {$[6]$} \\
\hline \multirow{2}{*}{ Educationally Competitive District Indicator $\left(C_{d}\right)$} & $13.778 * *$ & $9.385 * * *$ & $8.670 * * *$ & $10.451 * *$ & $14.596^{* *}$ & $14.322 * *$ \\
\hline & {$[6.271]$} & {$[2.800]$} & [3.163] & [4.273] & [7.067] & {$[7.017]$} \\
\hline \multirow{2}{*}{ Post RTE Indicator $\left(R T E_{t}\right)$} & 0.797 & 1.183 & 0.622 & 0.683 & $-3.637 * *$ & $-3.654 * *$ \\
\hline & {$[2.723]$} & [2.709] & {$[2.745]$} & {$[2.738]$} & {$[1.594]$} & {$[1.598]$} \\
\hline \multirow{2}{*}{ Differential Impact $\left(R T E_{t} \times C_{d}\right)$} & $32.038 * *$ & $37.395 * *$ & $37.150 * *$ & $35.368 * *$ & $35.135 * * *$ & $35.410 * * *$ \\
\hline & {$[13.544]$} & {$[16.841]$} & [16.840] & {$[15.476]$} & {$[12.867]$} & [12.941] \\
\hline \multirow{2}{*}{ Population } & 0.000 & & 0.000 & 0.000 & 0.000 & 0.000 \\
\hline & {$[0.000]$} & & {$[0.000]$} & {$[0.000]$} & {$[0.000]$} & {$[0.000]$} \\
\hline \multirow{2}{*}{ Share of Manufacturing } & $-0.123 * *$ & & $-0.122 * *$ & $-0.122 * *$ & $-0.125 * *$ & $-0.125 * *$ \\
\hline & {$[0.056]$} & & {$[0.055]$} & {$[0.055]$} & {$[0.056]$} & {$[0.056]$} \\
\hline \multirow{2}{*}{ Anticipatory 24-month Trend } & & & & 1.143 & & 1.139 \\
\hline & & & & {$[0.755]$} & & {$[0.845]$} \\
\hline \multirow{2}{*}{ Constant } & -0.770 & -1.877 & -0.598 & -0.659 & -0.529 & -0.518 \\
\hline & {$[1.716]$} & {$[1.715]$} & {$[1.732]$} & {$[1.724]$} & {$[1.710]$} & [1.709] \\
\hline Observations & 63,954 & 63,954 & 63,954 & 63,954 & 63,954 & 63,954 \\
\hline R-square & 0.055 & 0.056 & 0.056 & 0.055 & 0.056 & 0.055 \\
\hline $\begin{array}{l}\text { Monthly anticipatory indicators in competitive } \\
\text { districts ( } 24 \text { month) }\end{array}$ & No & Yes & Yes & No & Yes & No \\
\hline
\end{tabular}

Note: Dependent variable: number of new tuition centers per billion population monthly in each district. Sample is January 2001 to March 2015 . All regressions include state and month fixed effects. Standard errors clustered at the district level. Competitive districts are those with an IIT established before enactment of RTE in 2009. ${ }^{*} \mathrm{p}<0.10,{ }^{* *} \mathrm{p}<0.05,{ }^{* * *} \mathrm{p}<0.01$. 2. The joint test of dummies for 24 -month anticipatory effects in Column 3 and 5 is statistically significant at 1 percent respectively. 
Table 4: Testing parallel trends for new private school and HEI registrations per billion persons

\begin{tabular}{|c|c|c|c|c|}
\hline \multirow{2}{*}{ Independent Variables } & \multicolumn{2}{|c|}{$\begin{array}{c}\text { New private school registrations per } \\
\text { billion persons }\end{array}$} & \multicolumn{2}{|c|}{$\begin{array}{l}\text { New HEI registrations per billion } \\
\text { persons }\end{array}$} \\
\hline & {$[1]$} & {$[2]$} & {$[3]$} & {$[4]$} \\
\hline \multirow{2}{*}{$\begin{array}{l}\text { Educationally Competitive District Indicator } \\
\left(C_{d}\right)\end{array}$} & -4.644 & -4.143 & -1.353 & 3.192 \\
\hline & {$[12.303]$} & {$[12.395]$} & {$[50.590]$} & {$[50.778]$} \\
\hline \multirow{2}{*}{ Time Trend $(t)$} & 0.009 & 0.009 & 0.062 & 0.056 \\
\hline & {$[0.007]$} & {$[0.007]$} & {$[0.073]$} & {$[0.073]$} \\
\hline \multirow{2}{*}{ Differential trend $\left(t \times C_{d}\right)$} & 0.028 & 0.028 & 0.059 & 0.056 \\
\hline & {$[0.046]$} & {$[0.047]$} & {$[0.186]$} & {$[0.186]$} \\
\hline \multirow{2}{*}{ Population } & & 0.000 & & $0.000 *$ \\
\hline & & {$[0.000]$} & & {$[0.000]$} \\
\hline \multirow{2}{*}{ Share of Manufacturing [\%] } & & -0.012 & & -0.008 \\
\hline & & {$[0.011]$} & & {$[0.099]$} \\
\hline \multirow{2}{*}{ Constant } & -1.917 & -2.385 & -6.379 & -16.415 \\
\hline & [2.027] & [2.103] & [20.815] & [20.901] \\
\hline Observations & 26,928 & 26,928 & 26,928 & 26,928 \\
\hline R-square & 0.001 & 0.017 & 0.001 & 0.120 \\
\hline State fixed effects & No & Yes & No & Yes \\
\hline
\end{tabular}

Note: Dependent variable: (col. 1-2) number of new schools per billion population monthly in each district; (col. 3-4) number of new HEI per billion population monthly in each district. Sample is January 2001 to December 2006. Standard errors clustered at the district level. Competitive districts are those with an IIT established before enactment of RTE in $2009 . \quad * \mathrm{p}<0.10, * * \mathrm{p}<0.05, * * * \mathrm{p}<0.01$ 


\section{Table 5: Effect of RTE on new private school registrations and new HEI registrations per billion persons}

\begin{tabular}{|c|c|c|c|c|c|c|}
\hline \multirow{3}{*}{ Independent Variables } & \multicolumn{3}{|c|}{$\begin{array}{c}\text { New privatechool registrations per billion } \\
\text { persons }\end{array}$} & \multicolumn{3}{|c|}{ New HEI registrations per billion persons } \\
\hline & \multicolumn{2}{|c|}{$R T E_{d}=1$ after August 2009} & \multirow{2}{*}{$\begin{array}{c}R T E_{t d}=1 \\
\text { after state } \\
\text { enactment of } \\
\text { RTE } \\
{[3]}\end{array}$} & \multicolumn{2}{|c|}{$R T E_{d}=1$ after August 2009} & \multirow{2}{*}{$\begin{array}{c}R T E_{t d}=1 \\
\text { after state } \\
\text { enactment of } \\
\text { RTE } \\
{[6]}\end{array}$} \\
\hline & [1] & [2] & & {$[4]$} & {$[5]$} & \\
\hline \multirow{2}{*}{$\begin{array}{l}\text { Educationally Competitive District Indicator } \\
\left(C_{d}\right)\end{array}$} & $6.598 *$ & $4.632 *$ & $7.224 *$ & $40.355^{*}$ & $24.330^{*}$ & $40.197 *$ \\
\hline & {$[3.568]$} & [2.487] & {$[3.694]$} & [21.297] & [13.651] & [23.018] \\
\hline \multirow[t]{2}{*}{ Post RTE Indicator $\left(R T E_{t}\right)$} & 0.385 & 0.318 & -1.071 & -11.717 & -12.265 & $-15.387 * *$ \\
\hline & {$[1.005]$} & [1.011] & {$[0.687]$} & {$[9.564]$} & {$[9.590]$} & [7.483] \\
\hline \multirow{2}{*}{ Differential Impact $\left(R T E_{t} \times C_{d}\right)$} & $10.173 * *$ & $12.141 * *$ & 8.597* & $44.289 * *$ & $60.329 * *$ & 25.906 \\
\hline & {$[4.257]$} & [4.939] & {$[4.662]$} & {$[18.506]$} & [27.225] & {$[17.456]$} \\
\hline \multirow[t]{2}{*}{ Population } & 0.000 & 0.000 & 0.000 & $0.000 *$ & $0.000 *$ & $0.000^{*}$ \\
\hline & {$[0.000]$} & {$[0.000]$} & {$[0.000]$} & {$[0.000]$} & {$[0.000]$} & {$[0.000]$} \\
\hline \multirow[t]{2}{*}{ Share of Manufacturing [\%] } & -0.034 & -0.034 & -0.035 & $-0.340 * *$ & $-0.338 * *$ & $-0.343 * *$ \\
\hline & {$[0.023]$} & {$[0.023]$} & {$[0.023]$} & {$[0.151]$} & {$[0.150]$} & {$[0.153]$} \\
\hline \multirow[t]{2}{*}{ Constant } & $-1.265^{* * *}$ & $-1.199 * * *$ & $-1.206^{* * *}$ & $23.653 * * *$ & $24.188 * * *$ & $24.747 * * *$ \\
\hline & {$[0.306]$} & {$[0.316]$} & [0.294] & {$[8.320]$} & [8.336] & [8.172] \\
\hline Observations & 63,954 & 63,954 & 63,954 & 63,954 & 63,954 & 63,954 \\
\hline R-square & 0.021 & 0.023 & 0.022 & 0.107 & 0.108 & 0.108 \\
\hline Inclusion of 24-month anticipatory effects & No & Yes & Yes & No & Yes & Yes \\
\hline
\end{tabular}

Note: Dependent variable: (col. 1-3) number of new school registrations per billion population monthly in each district; (col. 4-6) number of new HEI registrations per billion population monthly in each district. Sample is January 2001 to March 2015. All regressions include state and month fixed effects. Standard errors clustered at the district level. Competitive districts are those with an IIT established before enactment of RTE in 2009. $* p<0.10, * * p<0.05, * * * p<0.01 .2$. The joint test of dummies for 24 month anticipatory effects in Column 3 and 5 is statistically significant at 5 percent. 
Table 6: Summary of differential impact $\left(R T E_{t} \times C_{d}\right)$ on registrations per billion persons under alternative definitions of competitive districts

\begin{tabular}{|c|c|c|c|c|c|c|c|}
\hline \multirow{3}{*}{$\begin{array}{l}\text { Differential Impact }\left(R T E_{t} \times C_{d}\right) \\
\text { by definitions of competitive districts }\end{array}$} & \multirow{3}{*}{$\begin{array}{c}\text { N. of } \\
\text { competitive } \\
\text { districts }\end{array}$} & \multicolumn{3}{|c|}{$\mathrm{RTE}=1$ after August 2009} & \multicolumn{3}{|c|}{$\mathrm{RTE}=1$ after state enactment } \\
\hline & & $\begin{array}{l}\text { New Tuition } \\
\text { registrations } \\
\text { per billion } \\
\text { persons }\end{array}$ & $\begin{array}{l}\text { New School } \\
\text { registrations } \\
\text { per billion } \\
\text { persons }\end{array}$ & $\begin{array}{l}\text { New HEIs } \\
\text { registrations } \\
\text { per billion } \\
\text { persons }\end{array}$ & $\begin{array}{l}\text { New Tuition } \\
\text { registrations } \\
\text { per billion } \\
\text { persons }\end{array}$ & $\begin{array}{l}\text { New School } \\
\text { registrations } \\
\text { per billion } \\
\text { persons }\end{array}$ & $\begin{array}{l}\text { New HEIs } \\
\text { registrations } \\
\text { per billion } \\
\text { persons }\end{array}$ \\
\hline & & [1] & [2] & [3] & [4] & [5] & [6] \\
\hline \multirow{2}{*}{ IIT before 2001} & \multirow{2}{*}{6} & 41.842 & $15.093 *$ & 62.656 & 31.476 & 6.618 & -19.637 \\
\hline & & [33.642] & {$[8.260]$} & [54.594] & [24.395] & {$[4.462]$} & [13.495] \\
\hline \multirow{2}{*}{$\begin{array}{l}\text { IIT and premier institutions } \\
\text { established before } 2001\end{array}$} & \multirow{2}{*}{9} & $47.210 * *$ & $15.225^{* *}$ & $78.009 * *$ & $39.869 * *$ & $10.963 *$ & 25.588 \\
\hline & & [22.982] & [6.594] & {$[37.574]$} & [16.970] & [6.292] & [23.895] \\
\hline \multirow{2}{*}{$\begin{array}{l}\text { Premier institutions established before } \\
2001\end{array}$} & \multirow{2}{*}{39} & $14.483 * *$ & $6.778 * * *$ & $35.398 * * *$ & $13.281 * *$ & $5.227 * * *$ & $22.199 * *$ \\
\hline & & {$[6.636]$} & {$[2.069]$} & [13.663] & [5.802] & {$[2.027]$} & [11.168] \\
\hline \multirow{2}{*}{ Any prior registrations (1991-2000) } & \multirow{2}{*}{89} & $18.962 * * *$ & $5.326 * * *$ & $28.630 * * *$ & $16.871 * * *$ & $3.511 * *$ & $13.549 * *$ \\
\hline & & {$[4.863]$} & {$[1.390]$} & [9.031] & {$[4.614]$} & {$[1.569]$} & [6.373] \\
\hline \multirow{2}{*}{ Any prior investments (1991-2000) } & \multirow{2}{*}{82} & $20.226 * * *$ & $5.806 * * *$ & $30.906 * * *$ & $18.291 * * *$ & $3.817 * *$ & $14.559 * *$ \\
\hline & & [5.243] & {$[1.496]$} & {$[9.740]$} & {$[4.966]$} & [1.699] & {$[6.848]$} \\
\hline
\end{tabular}

Note: Each cell provides estimates from a separate regression of the outcome identified in the column heading for the specific definition of competitive districts in each row. Sample is January 2001 to March 2015. All regressions include population, share of manufacturing and software firm registrations, 24-month anticipatory effects, state and month fixed effects. Standard errors clustered at the district level. ${ }^{*} \mathrm{p}<0.10,{ }^{* *} \mathrm{p}<0.05,{ }^{* * *} \mathrm{p}<0.01$. The joint test of dummies for 24-month anticipatory effects is statistically significant at 5 percent. 
Table 7: Percentage of enrolment by school type of current students - on the basis of IIT established before RTE [IHDS]

\begin{tabular}{|c|c|c|c|c|c|c|c|}
\hline \multirow[b]{2}{*}{ Type of Districts } & \multirow{2}{*}{$\begin{array}{l}\text { Type of } \\
\text { School }\end{array}$} & \multicolumn{3}{|c|}{ Primary (\%) } & \multicolumn{3}{|c|}{ Upper Primary (\%) } \\
\hline & & $\begin{array}{c}\text { Pre RTE } \\
{[2004-05]}\end{array}$ & $\begin{array}{l}\text { Post RTE } \\
\text { [2011-12] }\end{array}$ & Difference & $\begin{array}{c}\text { Pre RTE } \\
{[2004-05]}\end{array}$ & $\begin{array}{l}\text { Post RTE } \\
\text { [2011-12] }\end{array}$ & Difference \\
\hline \multirow{2}{*}{ Less-Competitive } & Government & 71.20 & 61.64 & -9.56 & 67.41 & 66.98 & -0.43 \\
\hline & Private & 24.43 & 34.49 & 10.06 & 23.67 & 26.69 & 3.02 \\
\hline \multirow{2}{*}{$\begin{array}{l}\text { Educationally- } \\
\text { Competitive }\end{array}$} & Government & 69.17 & 49.03 & -20.14 & 60.93 & 52.52 & -8.41 \\
\hline & Private & 26.10 & 49.08 & 22.98 & 29.16 & 43.89 & 14.73 \\
\hline \multirow{2}{*}{$\begin{array}{l}\text { Difference-in- } \\
\text { Difference }\end{array}$} & Government & & & -10.58 & & & -7.98 \\
\hline & Private & & & 12.92 & & & 11.71 \\
\hline
\end{tabular}

Note: 1. The difference-in-difference (in percentage points) is derived by undertaking the following steps: (a) subtract the percentage of students currently enrolled in a particular type of school during pre-RTE period from the post-RTE period for competitive and less-competitive districts, and (b) take the derived value from (a) and subtract the percentage points for less-competitive district from competitive districts. 2. A positive value of the difference-in-difference means that students attending a particular education level in a particular school type has increased in competitive districts relative to less-competitive districts during the post-RTE period in comparison to pre-RTE period. 3. A negative value of the difference-in-difference means that students attending a particular education level in a particular school type has increased in less-competitive districts relative competitive districts during the post-RTE period in comparison to pre-RTE period. 4. The category of school type include (a) Government, (b) Private, (c) Government-Aided, and (d) Others [Madrasa and Open schools]. We present the enrolment percentage in government and private schools since it constitutes 98 percent of enrolment in India. 5. For this calculation, we consider only the household and individuals which were surveyed in both time periods - 2004-05 and 2011-12. We make use of appropriate sample weights to arrive at the percentages of enrolment. 6. Similar statistic under alternative definition of competitive districts is provided in Appendix Table 40.

Source: Calculated by the authors on the basis of data made available from the India Human Development Survey [IHDS] 2004-05 and 2011-12 
Table 8: Status of private tuition take-up by education level - IITs established before RTE [IHDS]

\begin{tabular}{|c|c|c|c|c|c|c|c|}
\hline \multirow[b]{2}{*}{$\begin{array}{l}\text { Type of } \\
\text { District }\end{array}$} & \multirow[b]{2}{*}{$\begin{array}{l}\text { Type of } \\
\text { School }\end{array}$} & \multicolumn{3}{|c|}{ Primary } & \multicolumn{3}{|c|}{ Upper Primary } \\
\hline & & $\begin{array}{c}\text { Pre RTE } \\
{[2004-} \\
05]\end{array}$ & $\begin{array}{c}\text { Post } \\
\text { RTE } \\
{[2011-} \\
12]\end{array}$ & Difference & $\begin{array}{c}\text { Pre RTE } \\
\text { [2004-05] }\end{array}$ & $\begin{array}{l}\text { Post RTE } \\
\text { [2011-12] }\end{array}$ & Difference \\
\hline \multirow{3}{*}{$\begin{array}{l}\text { Less- } \\
\text { Competitive }\end{array}$} & Government & 13.71 & 20.24 & 6.53 & 20.17 & 25.09 & 4.92 \\
\hline & Private & 22.93 & 26.76 & 3.83 & 27.51 & 26.84 & -0.67 \\
\hline & Total & 16.15 & 22.44 & 6.29 & 21.98 & 25.62 & 3.64 \\
\hline \multirow{3}{*}{ Competitive } & Government & 6.57 & 15.82 & 9.25 & 8.48 & 18.98 & 10.50 \\
\hline & Private & 26.57 & 31.11 & 4.54 & 29.03 & 37.63 & 8.60 \\
\hline & Total & 13.66 & 23.54 & 9.88 & 18.35 & 29.09 & 10.74 \\
\hline \multirow{3}{*}{$\begin{array}{l}\text { Difference- } \\
\text { in } \\
\text { Difference }\end{array}$} & Government & & & 2.72 & & & 5.58 \\
\hline & Private & & & 0.71 & & & 9.27 \\
\hline & Total & & & 3.59 & & & 7.10 \\
\hline
\end{tabular}

Note: 1 . The difference-in-difference (in percentage points) is derived by undertaking the following steps: (a) subtract the percentage of students accessing private tuition who are currently attending primary/upper-primary in a particular type of school during pre-RTE period from the post-RTE period for competitive and less-competitive districts, and (b) take the derived value from (a) and subtract the percentage points for less-competitive district from competitive districts. 2. A positive value of the difference-in-difference means that the students accessing private tuition has increased in competitive districts relative to less-competitive districts during the post-RTE period in comparison to pre-RTE period. 3. A negative value of the difference-in-difference means that the students accessing private tuition has increased in less-competitive districts relative competitive districts during the post-RTE period in comparison to pre-RTE period. 4. The category of school type include (a) Government, (b) Private, (c) Government-Aided, and (d) Others [Madrasa and Open schools]. 5. For this calculation, we consider only the household and individuals which were surveyed in both time periods - 2004-05 and 2011-12.6. We make use of appropriate sample weights to arrive at the percentage of student accessing private tuition. 7. Similar statistic under alternative definitions of competitive districts is provided in Appendix Table 41.

Source: Calculated by the authors on the basis of data made available from the India Human Development Survey [IHDS] 2004-05 and 2011-12 
Table 9: Learning outcome scores of the first and second child in the age group 8-11 years old - IITs established before RTE [IHDS]

\begin{tabular}{|c|c|c|c|c|c|c|}
\hline \multirow{2}{*}{$\begin{array}{l}\text { Learning } \\
\text { outcome }\end{array}$} & \multirow{2}{*}{$\begin{array}{l}\text { Tuition } \\
\text { Status }\end{array}$} & \multicolumn{2}{|c|}{ Pre RTE [2004-05] } & \multicolumn{2}{|c|}{ Post RTE [2011-12] } & \multirow{2}{*}{$\begin{array}{l}\text { Difference- } \\
\text { in- } \\
\text { Difference }\end{array}$} \\
\hline & & $\begin{array}{c}\text { Less- } \\
\text { competitive }\end{array}$ & Competitive & $\begin{array}{c}\text { Less- } \\
\text { Competitive }\end{array}$ & Competitive & \\
\hline \multirow{4}{*}{$\begin{array}{l}\text { Reading } \\
\text { Ability }\end{array}$} & \multirow{2}{*}{$\begin{array}{l}\text { No } \\
\text { Tuition }\end{array}$} & 66.27 & 62.27 & 65.81 & 62.92 & 1.11 \\
\hline & & {$[0.61]$} & {$[3.67]$} & {$[0.59]$} & [3.09] & {$[2.40]$} \\
\hline & \multirow{2}{*}{ Tuition } & 80.08 & 75.3 & 76.1 & 87.63 & $16.30 * * *$ \\
\hline & & {$[0.86]$} & {$[2.93]$} & [0.93] & {$[2.43]$} & [3.71] \\
\hline \multirow{4}{*}{ Math Ability } & \multirow{2}{*}{$\begin{array}{l}\text { No } \\
\text { Tuition }\end{array}$} & 58.97 & 53.89 & 57.24 & 60.05 & $7.88 * * *$ \\
\hline & & {$[0.52]$} & [2.99] & {$[0.49]$} & {$[2.06]$} & [2.69] \\
\hline & \multirow{2}{*}{ Tuition } & 74.34 & 71.48 & 69.09 & 70.83 & 4.59 \\
\hline & & {$[0.97]$} & {$[3.56]$} & {$[0.87]$} & {$[2.78]$} & [4.87] \\
\hline \multirow{4}{*}{$\begin{array}{l}\text { Writing } \\
\text { Ability }\end{array}$} & \multirow{2}{*}{$\begin{array}{l}\text { No } \\
\text { Tuition }\end{array}$} & 53.82 & 53.69 & 55.75 & 54.60 & -1.02 \\
\hline & & {$[0.33]$} & {$[2.01]$} & {$[0.31]$} & {$[2.24]$} & {$[1.57]$} \\
\hline & \multirow{2}{*}{ Tuition } & 60.06 & 58.8 & 60.59 & 64.48 & $5.16 *$ \\
\hline & & {$[0.57]$} & {$[2.28]$} & {$[0.44]$} & {$[1.01]$} & {$[2.73]$} \\
\hline
\end{tabular}

Note: 1 . The above represents the mean and standard deviation [in parentheses] of reading, math, and writing ability of the first and second child in the age group 8-11 years old. We present the average scores by those who are taking tuition and not for each time period (pre/post RTE) and type of competitive district under the definition of IITs established before the enactment of RTE. 3. For this calculation, we consider only the household and individuals which were surveyed in both time periods - 2004-05 and 2011-12. We make use of appropriate sample weights to arrive at the average scores. 4. The last column reports the difference-in-difference in average scores between competitive and less-competitive districts, obtained pre and post RTE period. 5. The signs ***, **, and * represent the statistical significance at 1 percent, 5 percent, and 10 percent respectively. 6 . Similar statistic under alternative definitions of competitive districts is provided in Appendix Table 43.

Source: Calculated by the authors on the basis of data made available from the India Human Development Survey [IHDS] 2004-05 and 2011-12 


\section{Figure 1: Graphical representation of parallel trends of new tuition centers registrations per billion persons}

Note: The estimates were derived from regressing the new tuition centers registrations per billion persons on dummy for competitive districts interacted with dummies for year. Standard errors clustered at the district level. Competitive districts have an IIT located in them before the enactment of RTE in August 2009 by Government of India. The bandwidths represent the 95 percent confidence interval. 
Figure 2: Graphical representation of parallel trends of new school and HEIs registrations per billion persons

Note: The estimates were derived from regressing the new school and HEIs registrations per billion persons on dummy for competitive districts interacted with dummies for year. Standard errors clustered at the district level. Competitive districts have an IIT located in them before the enactment of RTE in August 2009 by Government of India. The bandwidths represent the 95 percent confidence interval. 


\section{Conflict of Interest}

None

Chirantan Chatterjee, Eric Hanushek, and Shreekanth Mahendiran \\ Confict of Interest}

